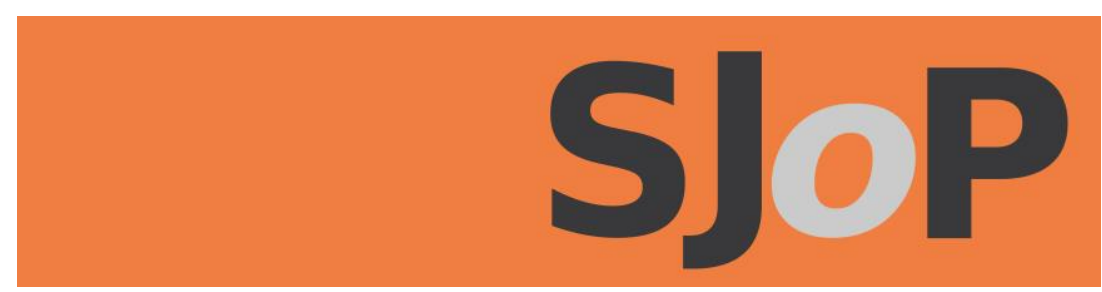

Scottish Journal of Performance

Volume 5, Issue 2

September 2018

ISSN: 2054-1953 (Print) / ISSN: 2054-1961 (Online)

www.scottishjournalofperformance.org

SJoP is supported by

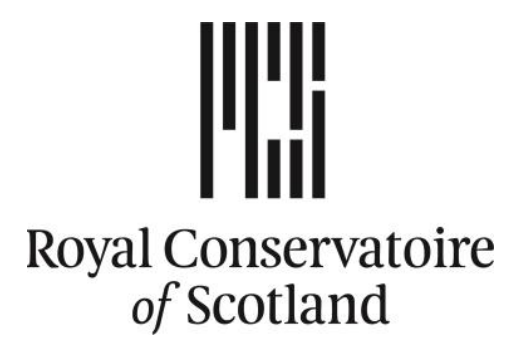




\section{About us}

The Scottish Journal of Performance is an open access refereed journal which aims to promote and stimulate discussion, development and dissemination of original research, focusing both on performance in Scotland (contemporary and historical) and / or wider aspects of performance presented by scholars and reflective practitioners based at Scottish academic institutions.

Published bi-annually and run by doctoral students, the Scottish Journal of Performance welcomes submissions from both established and early career researchers and operates a peer review system ensuring presentation of quality research in performance.

Performance in this context encompasses a wide range of arts and entertainment and takes as central themes dance, drama, film, music and television. The Scottish Journal of Performance takes as a key focus the creation and execution of performance in various contexts, encouraging the adoption of a wide range of range of research methods and approaches.

\section{Editorial Team}

Co-editor: Benjamin Redman (Royal Conservatoire of Scotland)

(editors@scottishjournalofperformance.org)

Web Editor: Lucy Hollingworth (Royal Conservatoire of Scotland)

Review Editors: Victoria Bianchi (University of the West of Scotland), Shona Mackay (Royal Conservatoire of Scotland)

Copy Editors: Iain Harvie (Royal Conservatoire of Scotland), Anika Marschall (University of Glasgow), James Slimings (Royal

Conservatoire of Scotland)

\section{Editorial Advisory Board}

Professor Stephen Broad (Royal Conservatoire of Scotland)

Dr Ben Fletcher-Watson (University of Edinburgh)

Dr Sophia Lycouris (University of Edinburgh)

Wendy Timmons (University of Edinburgh)

Dr Bethany Whiteside (Royal Conservatoire of Scotland)

\section{Copyright information}

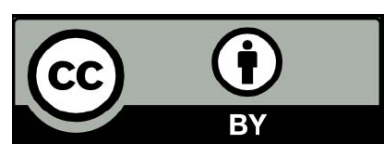

This work is licensed under a Creative Commons Attribution 4.0 International License.

See http://creativecommons.org/licenses/by/4.0/ for details. 
Contents

5

Editorial

BENJAMIN REDMAN

11

Deaf people and the theatrical public sphere MICHAEL RICHARDSON \& DAVID THOMPSON

35

Practitioner report: Composing interaction: performativity in Mechanical TIMOTHY COOPER

61

Practitioner report: I Gladly Strained My Eyes to Follow You: a guided tour of Pollok House SHAUNA MCMULLAN

85

Interview: Trio HLK BENJAMIN REDMAN

103

Book review: Reasons to be Graeae: a work in progress, edited by Jenny Sealey BEN FLETCHER-WATSON

107

Book review: Gender, subjectivity, and cultural work: the classical music profession, by

Christina Scharff LUCY HOLLINGWORTH

113

Book Review: Musicians in the making: pathways to creative performance, edited by John Rink, Helena Gaunt, Aaron Williamon BENJAMIN REDMAN 



\section{Editorial}

BENJAMIN REDMAN

DOI: 10.14439/sjop.2018.0502.01

Publication date: 30 September 2018

This issue explores a range of performance contexts: theatre, guided tours, audience interaction and reaction, music performance, and composition. Themes of creativity, invention, feminism, inclusion, and advocacy for $\mathrm{D} /$ deaf and disabled rights permeate these different contexts.

On the subject of creativity, Mary Wollstonecraft Shelley wrote:

Every thing must have a beginning ... and that beginning must be linked to something that went before ... Invention, it must be humbly admitted, does not consist in creating out of void, but out of chaos; the materials must, in the first place, be afforded: it can give form to dark, shapeless substances, but cannot bring into being the substance itself ... Invention consists in the capacity of seizing on the capabilities of a subject, and in the power of moulding and fashioning ideas suggested to it.

Shelley found fame as the author of Frankenstein: or, the modern Prometheus, first published in 1818; the quote above comes from the introduction to the 1831 edition. There have been a number of events marking the bicentenary of the publication of her novel, including the University of Dundee's 'Frankenstein 200' programme, and public talks, symposia and film screenings at Edinburgh 
Napier University. Shelley lived in Dundee for two years as a teenager, and later recounts, 'It was beneath the trees of the grounds belonging to our house, or on the bleak sides of the woodless mountains near, that my true compositions, the airy flights of my imagination, were born and fostered'.

Shelley was the daughter of Mary Wollstonecraft (17591797), author of $A$ vindication of the rights of woman (1792). Wollstonecraft was one of the founders of feminist philosophy and was highly influential on the suffrage movement. 2018 is the centenary of the Representation of the People Act, which granted some women (but not all) the right to vote. In recognition of Wollstonecraft's contribution to feminism and suffrage, there is an ongoing campaign 'Mary on the Green' to create a statue of her in Stoke Newington where she lived and worked. On the 'Mary on the Green' website, Mary Beard, Cambridge Professor of Classics, wrote in support, 'every woman who wants to make a difference to how this country is run, from the House of Commons to the pub quiz, has Mary Wollstonecraft to thank'.

Both Wollstonecraft and Shelley are mentioned by artist Sam Ainsley in Shauna McMullan's piece for this issue, I Gladly Strained My Eyes to Follow You: a guided tour of Pollok House. McMullan invited writers, academics, artists and Pollok House staff to respond to individual portraits of women on display in the house, producing a series of ecphrases-short pieces of writing made up of their reflections and thoughts in response to the (often anonymous) portraits. McMullan describes the project, and combines the individual author responses with feminist theory to argue for a more emancipated society.

Scottish virtuoso solo percussionist Dame Evelyn Glennie was diagnosed as being profoundly deaf by the age of 12 . Despite this apparent setback, she has become one of the 
most successful and high-profile classical musicians in the world. In her 2003 TED talk, How to truly listen, Glennie advocates for the rights of $\mathrm{D} /$ deaf and disabled performers:

...as I grew older, I then auditioned for the Royal Academy of Music in London, and they said, "Well, no, we won't accept you, because we haven't a clue ... of the future of a so-called 'deaf musician"'. And I just couldn't quite accept that. And so, therefore, I said to them, "Well, look ... if you refuse me through those reasons, as opposed to the ability to perform and to understand and love the art of creating sound-then we have to think very, very hard about the people you do actually accept”. And, as a result ... they accepted me. And not only that ... it changed the whole role of the music institutions throughout the United Kingdom. Under no circumstances were they to refuse any application whatsoever on the basis of whether someone had no arms, no legs-they could still perhaps play a wind instrument if it was supported on a stand ... And every single entry had to be listened to, experienced, and then, based on the musical ability, then that person could either enter or not.

Glennie has recently collaborated with the critically acclaimed ensemble Trio HLK, performing a series of concerts (which are set to continue into 2019), and, along with saxophonist Steve Lehman, she features on the band's debut album, Standard time. In my interview with Richard Harrold and Richard Kass of Trio HLK, they speak warmly of their collaboration with Glennie and Lehman and discuss a range of topics, including their development as an ensemble, their compositional process, and planning concert programmes from an audience perspective. Relating to the quote from Shelley on creativity and 
invention that begins this editorial, the band have deconstructed existing jazz 'standard' tunes, and rearranged them to form new material.

Timothy Cooper reports on his interactive sound installation, Mechanical, that uses old and broken bicycle parts to create new sounds via computers and a speaker array. He describes the set-up of the installation, and goes on to explore and discuss the audience response to, and relationship with, the installation and the other players. $\mathrm{He}$ argues that the interaction elicits performative actions by the audience, and concludes that the interaction is characterised by the network between the audience members, their behaviours, and the bikes. $\mathrm{He}$ contextualises this through Simon Emmerson's notion of meaningful response and Sarah Rubidge's Performing installations (2009).

In Deaf people and the theatrical public sphere, Michael Richardson and David Thompson present their research into problems with accessibility for Deaf spectators in theatres. They argue that current initiatives designed to improve accessibility, including Sign Language Interpreted Performances, fail to give Deaf people an equivalent experience to their Hearing peers. They propose a 10-point 'best practice' checklist to assist theatre managers in improving the experience of Deaf theatregoers, and advocate for the development of a Deaf theatrical public sphere.

Ben Fletcher-Watson reviews Reasons to be Graeae: a work in progress, edited by Jenny Sealey. According to their website, 'Graeae is a force for change in world-class theatre, boldly placing $\mathrm{D} /$ deaf and disabled actors centre stage and challenging preconceptions'. The book combines a range of sources including interviews with actors and administrators, scripts and reviews, to chart the rise of 
Graeae to become the UK's leading disabled-led theatre company. In common with the Richardson and Thompson article, the book makes suggestions for marketing to D/deaf and disabled audiences, and advocates for greater accessibility and inclusion.

Lucy Hollingworth reviews Gender, subjectivity, and cultural work: the classical music profession, by Christina Scharff. The book examines how gender, race and class affect female musicians working in the classical music profession in London and Berlin. Scharff combines research using quantitative and qualitative analysis of interview data with feminist theory to critique inequality and exclusion. As with Mary Wollstonecraft some two centuries previously, Scharff challenges individual and societal assumptions, and proposes a more inclusive society.

Continuing the theme of creativity, I review Musicians in the making: pathways to creative performance, the first in a five-volume series published by Oxford University Press. The series is an outcome of a major research project at the Research Centre for Musical Performance as Creative Practice, which examined the development of the 'creative voice' of musicians. Musicians in the making includes contributions from internationally renowned researchers, performers, and academics, and combines theory with personal testimonies from musicians and performance teachers, including the former Principal of the Royal Conservatoire of Scotland, John Wallace.

Kirsty Kay stood down as Co-editor of SJoP after the publication of the sixth edition, having been Co-editor since issue three. The SJoP team would like to thank Kirsty for all her hard work and professionalism, and we send her our very best wishes for the future. We would also like to thank the Royal Conservatoire of Scotland for their continued support, Anglia Ruskin University, the editorial team, 
Scottish Journal of Performance

Volume 5, Issue 2

advisory board, our peer reviewers, funders, and especially our authors.

BENJAMIN REDMAN

Co-editor, Scottish Journal of Performance 


\title{
Deaf people and the theatrical public sphere
}

\author{
MICHAEL RICHARDSON \& DAVID THOMPSON
}

DOI: 10.14439/sjop.2018.0502.02

Publication date: 30 September 2018

The nature of any public sphere is that it embraces all private citizens: it is, in current parlance, accessible. The British theatre institution demonstrates a commitment to accessibility in its funding structures and performance programming. Much of the modern theatrical public sphere is, however, mediated not through performance itself, but rather through various framing activities. Marketing and audience development initiatives constitute the means by which theatre institutions engage in communication with their audiences and have more recently become increasingly dialogic through the use of social media and online criticism.

For Deaf people who use sign language, the principal method chosen by theatre managers to provide access is the Sign Language Interpreted Performance (SLIP). Research into SLIPs has suggested that the performance itself is not effective in giving Deaf people an equivalent participative experience to their Hearing peers. This paper goes further, and interrogates the framing activities of marketing and feedback. It argues that there is failure both to accommodate the visual (rather than auditory) orientation of Deaf people, and to use sign language when communicating with them. Consequently, Deaf people are excluded from the theatrical public sphere, and rather than providing access, theatre institutions contribute to undermining Deaf people's full citizenship. 
Keywords: performance in society, Deaf, audience, theatrical public sphere.

\section{Introduction}

The performance practices of disabled artists are well documented (see, for example, Kuppers, 2013). Hadley (2014) argues that disabled bodies also 'cause a commotion' (Sandahl and Auslander, 2005, p.2) in front of house areas. In contrast, the relative invisibility of Deafness ${ }^{1}$ often leaves Deaf people's needs ignored by Scottish mainstream producing and receiving theatres. Many of the current efforts to make performances accessible for Deaf people are ineffective, not only because the creative techniques employed during performances do not facilitate adequate actor-spectator interaction, but also because the activities that frame performances are grounded in a pervasive language ideology that excludes Deaf people. These framing activities constitute the pre- and post-performance communication between theatre institutions and their public. In the twenty-first century, when performances in mainstream theatres are arguably not often socio-politically impactful (Reinelt, 2011), it is these communications that trigger the creation of a theatrical public sphere. However, they are typically presented in society's dominant (spoken and / or written) language and consequently exclude Deaf people whose first language is a signed language.

This paper is co-authored: Michael, Hearing ${ }^{2}$, is conducting doctoral research into the participation of Deaf people in theatre; David, Deaf, is an active theatre-goer who has been campaigning for over two decades for theatres in Scotland to improve their services for Deaf people. The paper begins with an introduction to the notion of the theatrical public sphere and its location in contemporary mainstream theatre practice predominantly in pre- and postperformance activity. Following a brief introduction to the Deaf community and the Sign Language Interpreted 
Performance (SLIP), the typical means by which Deaf people are encouraged to attend mainstream theatre, the article goes on to present the methods and results of a study into the effectiveness of SLIPs. We argue that the processes within which SLIPs are framed actually exclude Deaf people from the theatrical public sphere; we propose a number of easily achievable additions to the communication activities of venues that would include Deaf spectators and prevent theatres from unwittingly denying full citizenship to Deaf people.

\section{The history and development of the theatrical public sphere}

When Habermas (1989) introduced his concept of the bourgeois public sphere, he was referring not to a specific physical space, but to something more akin to a Bourdieusian field in which individuals and institutions interact (Balme, 2014). Such a field is genuinely public when it is open to all private citizens to come together, to discuss the social and political issues of the day, and ultimately, to influence or challenge the actions of the dominant strata of society: it is 'political participation ... enacted through the medium of talk' (Fraser, 1990, p.57). In practice, the protopublic sphere of the late sixteenth century was dominated by the aristocracy, who met in relatively exclusive coffee shops. However, from the early seventeenth century, theatres (such as The Globe in London), concert halls, and museums offered more accessible and inclusive locations as public meeting spaces for people from all social classes. A more encompassing public sphere began to develop, although it remained available predominantly to property owning, educated, white men. Despite its idealistic goal of inclusion, women and those of lower social status were unwelcome (Fraser, 1990). Deaf people were also excluded, triply compromised by their inability to interact using speech (the dominant form of communication), by their 
inadequate education, and by the law that prevented Deaf people from owning property (Sacks, 1991).

A public sphere in which ordinary citizens can debate matters of public interest regardless of their background is necessarily dependent on free speech, and by implication, freedom of artistic expression. In the pre- and early modern theatrical public sphere, the institution of the theatre, the plays it chose to perform and the way it broadcast itself all acted as stimulants to public debate. Additionally, the provision of a range of architectural spaces within theatre buildings supported several foci for communication, of which the stage was only one (Balme, 2014). The mideighteenth century view that the stage reflected society back on itself was central to the notion of a politically efficacious theatrical public sphere, with potentially revolutionary consequences. Indeed, Beaumarchais' play The Marriage of Figaro was initially banned by Louis XVI and several censors for its satirical content (Wood, 1964, p.30). One contemporary commentator felt it marked 'the end of the old order' (ibid.) by putting into the public sphere the social and political unease that was already being expressed privately. Mozart and da Ponte's operatic version of the same story was widely felt to have contributed actively to fomenting the French Revolution of 1789 (ibid.).

Reinelt (2011) argues that twenty-first century mainstream theatre has, to a large extent, lost this ability to be politically active, not least because of prevalent funding regimes in which budgets are underwritten by the very sectors of society that writers and directors might wish to critique. Even when plays are politically provocative, the conditions of audience reception in modern theatres resemble more a multitude of private spaces rather than a single public one. It is more than a century since the audience sat in the light, using the theatrical event as an occasion for personal display and public interaction (Kennedy, 2009). Instead, the 
typical theatre has a darkened auditorium in which spectators are encouraged to focus on the stage (Bennett, 1990) and to establish a personal interaction with the actors in that aesthetic space (Fischer-Lichte, 2014). Such prioritising of theatre aesthetics is not conducive to supporting the development of a theatrical public sphere; indeed, it can often only be seen to be effective if the performance engenders impact outside the auditorium at a later date, as Brecht (1964) aimed to achieve with his political theatre. For Habermas (1989), society has shifted from publicly critiquing culture (in its broadest sense) to passively consuming culture (in the narrower definition of the arts and heritage) in spaces which do not allow for public discourse and are thus essentially part of the private sphere. Rancière (2007), however, calls into question the views of those who, like Habermas, Brecht, and Artaud (1989), want to challenge this perceived passivity of spectators, arguing that spectatorship is always active, generating individual interpretation of what has been seen that may inform subsequent discussion with other spectators.

Production and audience reception are not the only means by which the theatrical public sphere is created; theatre exists within wider society and communicates with the institutions and individuals that make up that social space, through marketing and audience development initiatives. Playbills, posters, programmes, play scripts, specialist magazines, the arts pages of newspapers, and radio and television have all provided a medium for monologic communication by theatre institutions (Balme, 2014). More recently, online resources such as theatre blogs, social media and online criticism have allowed for a more dialogic relationship with audiences, again something advocated in the pre-digital age by Brecht: 'a theatre that makes no contact with the public is a nonsense' (1964, p.7). Together, these phenomena provide a trigger for a theatrical public sphere that is not centred on the stage, and which uses 
forms of communication that extend beyond performance. Such an active dialogic public sphere potentially recreates what Habermas originally invoked, and might reconnect the theatrical public sphere with the 'wider public sphere of genuinely important social and political issues' (Balme, 2014, p.73).

This paper argues, however, that the creation of the theatrical public sphere is not fully inclusive. Rather, it excludes the participation of Deaf people, even when the communication initiated by theatre institutions relates to performances that have been created with the specific intention of providing accessibility for the Deaf community. To consider this situation, it is necessary to briefly introduce the notion of Deaf culture, and the means by which Deaf people are encouraged to attend performances in mainstream theatres.

\section{The Deaf community and theatre}

The early conceptualisation of Deaf culture as a linguistic minority group by Carol Padden and Tom Humphries (1988) offers a cultural model of Deafness that foregrounds the use of a signed language as a first language, and the maintenance of familial and / or social ties with other people who self-identify as Deaf. The cultural model was initially presented as a valorisation of Deaf culture (Bechter, 2008), a defence against the increasing medicalisation of deafness, described by health professionals only in audiological terms as a hearing loss which should be 'cured' (Miller, Vandome and McBrewster, 2010). The rigid binary opposition between the cultural and medical models is now contested, and a range of Deaf ways of being are identified that reflect a number of potential language choices and audiological statuses (Corker, 1998; Bauman, 2008; Davis, 2008; Young and Temple, 2014). However, the early cultural model is useful here, as this article is grounded in research carried out with Deaf people who specifically choose to 
access theatre through the visual channel and the medium of sign language.

A number of features of sign languages are relevant here. Firstly, dialogic communication in sign language almost always necessitates bodily co-presence, relative proximity and direct visual contact ${ }^{3}$ (Bauman and Murray, 2013; Lockwood, 2014). Secondly, there is no practicable written form of any sign language (Conley, 2001; Woll, SuttonSpence and Elton, 2001). Whilst Deaf people often borrow from the written form of the local spoken language, this is usually their second language. Conrad (1979) described the low levels of written language literacy of Deaf people and this is little improved, even with greater use of hearing aids and cochlear implants (Harris, Terletski and Kyle, 2017). Accordingly, monologic communication with Deaf people can often be more effective using sign language video rather than written text. Finally, the use of signed languages by Deaf people has been oppressed by the Hearing majority since the mid-nineteenth century. The underlying ideology that privileges spoken (and written) languages operates hand in hand with 'audism': the notion, originally coined by Humphries (in an unpublished essay in 1975), that one is superior based on one's ability to hear (Bauman, 2004).

In theatre performances, the role of sign language in defining Deaf identity is fundamental, as was made clear by Miles and Fant (1976). These writers, both founder members of the National Theatre of the Deaf in the United States, formulated a definition of Deaf theatre that is still relevant today. They describe the genre as theatre created and performed in sign language, by Deaf actors, which puts on stage elements of the experience of Deaf people. This is unsurprising; most theatre audiences prefer to see performances that are performed in their own language, and feel a particular connection with productions in which their own experience is reflected back to them from the 
stage (Tulloch, 2005). Historically, many Deaf theatre performances took place in the separate 'DeafSpace' of Deaf clubs and schools (Atherton, 2009) although social and economic pressures have caused many of these institutions to close down in recent decades (Padden, 2008).

For Hearing theatre venue managers, sign language is seen as a mechanism for providing access for Deaf people, but not by programming Deaf theatre; instead, the prevailing paradigm for encouraging the attendance of Deaf spectators is the sign language interpreted performance (SLIP) ${ }^{4}$. SLIPs are performances of Hearing (spoken language) theatre scripts that are interpreted into sign language for Deaf spectators, often by a single interpreter (Rocks, 2015). Interpreting Deaf theatre for Hearing audiences in mainstream theatre buildings is unheard of, and the interpreter's role is seen exclusively as providing access for Deaf sign language users (Gebron, 2000). Following their introduction in London in the 1980s, SLIPs are now widespread throughout the UK. The typical model has the interpreter in the platform position, either onstage in a downstage corner, or just outside the proscenium arch, or on a small box on the auditorium floor (Gebron, 2000). The impetus to provide an interpreter is administrative rather than artistic, and consequently the interpreter is presented as aesthetically and spatially separate from the production (Richardson, 2018).

\section{Access to the theatrical public sphere}

There has been little research on SLIPs, and what research there is has been conducted predominantly by and with sign language interpreters. The literature highlights the complexities of theatrical sign language interpreting and the relative lack of support provided by theatre companies and theatre venues (Turner and Pollitt, 2002; Rocks, 2011; Ganz Horwitz, 2014). Others have written, from a Hearing perspective, of the relevance of performance skills to 
interpreters (Ruane, 2009; McDougall, 2015; Richardson, 2017). The research presented here complements those approaches by foregrounding the perspective of Deaf spectators at SLIPs.

The study involved Michael, in his role as researcher, attending a SLIP in a receiving venue (a city-centre, proscenium-arch theatre) accompanied by ten spectators. Five of the spectators were Hearing and five Deaf. Each group was constituted of people with a history of interest and participation in theatre, who might be assumed to have sophisticated and critical responses to performances. The Deaf group, which is the focus of this article, was recruited by David; he also participated in the project. The Deaf participants all self-identified as choosing to attend performances mediated in sign language: the two participants who used electronic aids to hearing did not have sufficient residual audiological function to access onstage speech.

Following the performance, Michael ran focus groups with each group lasting approximately 80 minutes, in the style of Sauter's (2000) Theatre Talks. The SLIP we attended was used as an elicitation tool, following the model of O'Brien's (2013) visual research with young Deaf people, with the intention of provoking responses about the group's experience of attending SLIPs in a range of mainstream producing and receiving theatres in cities across the central belt of Scotland. The Deaf focus group was conducted in sign language without an interpreter. Qualitative data (the responses of participants) were video recorded and subsequently transcribed (and thus translated into English) by Michael. The analysis prioritised the Deaf respondents, with the intention of making the study as methodologically and epistemologically 'Deaf-friendly' as possible (Young and Hunt, 2011). Quotes from the data are presented later in this article (in italics and unattributed to preserve anonymity). 
Only data from the Deaf group are presented, as this article is focused on the particular Deaf experience of attending a SLIP rather than on the delivery and broader impact of the interpreted performance on all spectators.

The strength of the data is its generation by (rather than about) Deaf people, and its collection by the researcher directly in sign language rather than through an interpreter. However, of necessity, the presentation of results involves translation into English, which is a highly subjective process. Furthermore, although Michael is fluent in BSL, it is not his first language. A further concern is the small size of the focus group, which suggests that the results are not generalisable. However, the Spearman Brown Prophecy Formula (Weller and Romney, 1988) suggests that when a group of respondents share cultural knowledge and generate similar data, then a large group is not required, and the results can be assumed to be representative beyond the experience of the respondents.

The intention of the study was to interrogate the effectiveness of SLIPs in providing access to Deaf spectators, or as Fischer-Lichte (2014) would have it, in allowing Deaf spectators to establish interactions with the actors from which they can construct the meaning of the play. The focus was on the theatrical space and the performance event, and the results strongly suggest that SLIPs are not effective in providing access. Interpreters are spatially separated from the actors in a visually neutral space, making it difficult to follow both simultaneously. Furthermore, they are rarely conceptualised as performers, instead treated by administrators as 'access technology' that can be 'plugged in' to a production at short notice (Richardson, 2018). Additionally, the creation of a sign language translation equivalent to the source text is problematic, especially when that source may incorporate not only spoken dialogue but also auditory components such 
as music and sound effects (Richardson, 2017). Each of these shortcomings of SLIPs compromises the performance's communication to its Deaf spectators.

From Michael's own experience as a spectator at SLIPs, these results were unsurprising. Unexpected, however, was the importance placed by the respondents on effective dialogic communication between theatre institutions and the Deaf community. They critiqued the establishment of a theatrical public sphere that is exclusive and directed predominantly at Hearing patrons, even when it concerns SLIPs and other performances which are intended to be inclusive.

If we return to Balme's (2014) list of mechanisms by which theatre institutions engage with their audiences, we find a variety of methods of communication that convey different information about a particular performance. Repertoire, actors' names, character lists, synopses, and reviews are all published with the intention of encouraging attendance. Furthermore, online forums give spectators the opportunity to critically discuss performances that they have seen. This reflects the processual nature of audience response, active before, during and after the performance across perceptual, cognitive, emotional and communicative dimensions (Bennett, 1990; Cremona, et al., 2004; Tulloch, 2005). Each contributes to Balme's notion of what constitutes the theatrical public sphere, and yet, the Deaf respondents describe them as exclusive, and not public (in the sense of being open access) at all.

The root of the problem is language choice, and for Deaf spectators, the solution is simple:

Signing gives access. 
However, despite the recognition that at least some Deaf people are accessing the performance through sign language, other communication between the institution and its Deaf public is not reoriented to the visual mode. Instead, the language ideologies of the Hearing hegemony negatively influence communication practices. Deaf spectators are expected to access the theatrical public sphere using their second language, which, as previously explained, is not necessarily an area of significant competence.

It need not be this way. To start at the beginning of the audience process, the respondents suggest that access to the theatrical public sphere would be improved if venue staff were more able to adopt the perspective of Deaf people and to respond to what Bahan (2014) calls their visual orientation to the world. This means recognising that English-language marketing material and websites are not accessible to many Deaf people. Short BSL videos would be more useful as marketing tools:

[If the theatre] had a signed synopsis of what the play is ... if they had clips like that, Deaf people could actually say 'Oh that's what it is about-no, I don't fancy that or yes, that looks really good'... That would make it a bit easier.

Furthermore, advertising repertoire in Deaf-friendly spaces is much more likely to encourage attendance than simply using the theatre's own website. It is not likely that Deaf people have a developed tradition of accessing Hearing theatre venues (Rocks, 2011), given their practice of socialising in their own separate 'DeafSpace' (Atherton, 2009), so an element of outreach is required to encourage engagement by the Deaf community. This is being made easier in the twenty-first century. In the place of gradually disappearing Deaf clubs and schools, the Deaf community is 
developing a virtual 'DeafSpace' on social media (Valentine and Skelton, 2008).

Adopting a visual perspective would also support Deaf spectators during their visit to the theatre, using preperformance talks delivered in BSL.

An interpreter explains the background to the story, how it was created, what it is about, and then moves on to pictures of the actors, matching faces to the characters' and their sign names.

An explanation of the synopsis, and the matching of actors to characters (ideally using photographs) and their sign names, would provide an element of pre-show preparation for Deaf spectators that is already more frequently offered to visually impaired audiences through onstage touch tours of the set and costumes.

Importantly, theatre institutions need to recognise the central role played by the interpreter in the experience of Deaf spectators at SLIPs. Advance information about the interpreter is essential.

Looking down the list of every show, it says it's interpreted but there's no name, no indication of standing on the right or left.

In the same way that different actors appeal to different people, so different interpreters are preferred by different Deaf spectators. Additionally, the position of the interpreter on stage is crucial in determining which seats to book in the auditorium, and could be included as supplementary information to the show advertising. It could also usefully be 
confirmed at each performance by visual signage within front of house spaces, to avoid later embarrassment.

If I see the interpreter is on the wrong side, it's too late, the show has started. How are you supposed to change?

Sitting at an excessive distance from the interpreter renders the SLIP pointless, as it is impossible to 'read' the sign language.

After the show, Deaf people also appreciate the opportunity to discuss the performance together, and to give feedback.

When it's finished we're back in the room, writing feedback and that's it, the end of the day. And we go there again and again.

Peter Eversmann describes such post-show discussion as an essential part of the audience reception process (Cremona, et al., 2004). For him it is a typically collective activity in which groups of spectators consider the performance cognitively, together analysing its meaning. For Deaf spectators, the provision of a space in the theatre for post-performance discussion in sign language would support the collective and collaborative nature of the community. Video cameras could be used to capture critical feedback that could subsequently be disseminated online. This is an achievable visually oriented alternative to the written language online discussion forums used by many Hearing theatre-goers.

Some of these recommendations are made by Solar Bear, a Scottish theatre company with experience of working with Deaf actors, in their best practice documents for accessible 
theatre (Solar Bear, n.d.), and within a Deaf audience development pack produced by Arts Council of Wales (2018). Best practice has been demonstrated since 2015 at Glasgow Film Theatre with its Visible Cinema Club (Glasgow Film Theatre, n.d.). Here, the venue is the instigator and provider of all the aids to accessibility, allowing for a coherent approach. In mainstream Scottish theatres, however, this is not the case. Instead, in some mainstream venues a Deaf Theatre Club is delivered by an independent organisation, Inkblot Collective (2016), that provides direct marketing to Deaf people, and pre- and postshow communication in sign language as described above. As an independent service, however, they are unable to directly influence the activity of venues, who do not themselves demonstrate widespread implementation of the available best practice advice. Accordingly, and in pursuit of equal access to the theatrical public sphere, we propose a best practice checklist for theatres to ensure appropriate and effective communication with Deaf spectators. This list has been developed predominantly by David from his own extensive experience of attending theatre advertised as accessible, supplemented by the responses of this study's Deaf focus group, and subsequently refined during several face-to-face and email conversations with Michael.

\section{Best practice checklist for theatres}

1. For each show, identify the ways in which it might be accessible for Deaf spectators-visual theatre with no dialogue, Deaf theatre in sign language, SLIP, captioned, super-titled opera-and add this information to all marketing material connected to the show.

2. In the case of a SLIP, add the name of the interpreter, the position in which they will stand (right or left side of the stage when looking from the audience 
perspective), and whether they are a local interpreter or touring with the production.

3. Upload the information from above to the theatre website and to the Access Scottish Theatre (or similar) website.

4. Upload to the theatre website recent photographs of the actors in the production and a sign language video giving information about the synopsis for each show that specifically targets Deaf spectators.

5. Use this 'Deaf-friendly' marketing material to target Deaf spectators through appropriate channels, for example, Deaf clubs and Deaf online spaces.

6. Hold seats for Deaf spectators that have a good view of both the interpreter and the stage: in the stalls, on the same side of the auditorium as the interpreter and approximately 10 to 12 rows back from the stage.

7. Set up a pre-performance talk in sign language, with recent photographs of actors and an opportunity to introduce not only the synopsis, but also the sign names for characters and locations. Market this to Deaf spectators and book an interpreter or other sign language user to deliver it.

8. Before the performance, indicate pictorially the position of the interpreter on auditorium doors, so that Deaf patrons can check they have the right seats before entering. Be prepared to offer replacement seats if the position of the interpreter has changed from that advertised. 
9. Ensure that programmes include photographs of the actors who will be performing, rather than standard publicity shots with actors who are no longer members of the cast.

10. After the show, provide a forum for post-show discussion in sign language. Video the feedback and use it for subsequent audience development.

\section{Conclusion}

Since the initial work of Habermas (1989), there has been ongoing interdisciplinary study on the public sphere, and a body of essays has been drawn together in an online forum (Koller, 2012). The mapping project that initially accompanied that forum, the Public Sphere Guide, is no longer available, but Balme (2014) reports that it suggests three dimensions to the public sphere: the production structures of public communication, the social stratification inherent in all forms of public communication, and the potential creation of counter-publics, groups that are excluded from the public sphere.

This article argues that the Hearing-Deaf stratification of public communication by theatre institutions contributes to the creation of a Deaf counter-public, by prioritising the language choices of the Hearing hegemony and paying little attention to the visual orientation of Deaf people. Historically, this has been inconsequential, as the widespread existence of Deaf clubs allowed for the creation of a separate and highly active Deaf public sphere. Current socio-political trends, however, favour access and participation, and the creation of one fully inclusive public sphere. The checklist above represents steps that support Deaf people to attend performances and thereafter to engage in public debate and discussion stimulated by that 
performance: they support Deaf people to be part of the theatrical public sphere.

Unfortunately, the current state of theatre's accessibility project is, for Deaf people, one of frustrating inadequacy. It represents one of many examples of the social contract between Deaf and Hearing communities being excessively phono-centric and audist. This paradigm denies Deaf people full citizenship by compromising their full participation in the institutions of civil, political, and social society through limiting the language of public discourse to that of the dominant community (Emery, 2009). The irony of the situation is inescapable: theatre institutions profess themselves committed to accessibility, and yet because they do not question their own language ideologies and fail to understand the visual orientation of Deaf people, they actually contribute to the institutional audism of Hearing society. If theatre genuinely hopes to attract Deaf spectators, be it through SLIPs or through other performance styles, it needs to consider every step of the production process, not just the performance event, and ensure that all communication with Deaf people is framed appropriately, for example by using the check-list proposed above.

It could be argued that the provision of opportunities for post-performance discussion in sign language will only lead to the creation of a different Deaf counter-public, not outside but within and subordinate to the Hearing theatrical public sphere. Warner (2002), however, suggests that such a counter-public is a public in its own right, formed as it is by the same performance trigger, and for Fraser (1990) a multiplicity of interacting publics is a more realistic and perhaps more desirable paradigm than an idealised fully inclusive public sphere. The challenge for the future is to find ways to stimulate dialogue between Deaf and Hearing public spheres, and on this matter, theatre could provide a 
meaningful pathway. In the meantime, supporting the development of a Deaf theatrical public sphere is a useful first step.

\section{Notes}

1. The capitalised form 'Deaf' is used conventionally to refer to those people who consider themselves part of a cultural linguistic group. Specifically in this article, 'Deaf' signifies those who choose to participate in theatre through the medium of sign language. ${ }^{\uparrow \uparrow}$

2. We adopt the convention, equivalent to 'Deaf', of using the capitalised 'Hearing' to signify cultural identity rather than audiological status. Specifically, we use it to refer to people who choose to participate in theatre (as actors, audience or programmers) that is mediated predominantly through spoken language and the auditory channel. ${ }^{[\uparrow]}$

3. More recently, innovations in video technology such as Skype, FaceTime and Glide have made possible sign language communication at a distance. ${ }^{\llbracket}$

4. Captioned and super-titled performances (including of opera) also provide access to those with an audiological hearing loss, although they may not be effective for Deaf people whose first language is a sign language. ${ }^{\Uparrow}$

5. Deaf people typically use a single sign as a name for an individual or location, rather than rendering their name in full using the manual alphabet. This is particularly important for theatre interpreters, who are likely to be too far away from Deaf spectators for fingerspelling to be easily read. ${ }^{\uparrow}$

\section{References}

Artaud, A., 1989. Artaud on theatre. Translated by C. Schumacher and B. Singleton. London: Methuen Drama.

Arts Council of Wales, 2018. Developing D/deaf, deafened and hard of hearing audiences in Wales: a toolkit for venues and theatre companies. [online] Available at:

〈http://www.celf.cymru/advice/online-equality-guide/138581.file.dld〉 [Accessed 22 February 2018].

Atherton, M., 2009. A feeling as much as a place: leisure, deaf clubs and the British deaf community. Leisure Studies, 28(4), pp.443-454.

Bahan, B., 2014. Senses and culture: exploring sensory orientations. In: H-D. L. Bauman and J. J. Murray, eds. Deaf gain: raising the stakes for human diversity. Minneapolis: The University of Minnesota Press, pp.233-254. 
Balme, C. B., 2014. The theatrical public sphere. Cambridge: Cambridge University Press.

Bauman, H-D. L., 2004. Audism: exploring the metaphysics of oppression. Journal of Deaf Studies and Deaf Education, 9(2), pp.239246.

Bauman, H-D. L., 2008. Introduction: listening to deaf studies. In: H-D. L. Bauman, ed. 2008. Open your eyes: deaf studies talking. Minneapolis: University of Minnesota Press, pp.1-33.

Bauman, H-D. L. and Murray, J. J., 2013. Deaf studies in the 21st century: "deaf-gain" and the future of human diversity. In: L. J. Davis, ed. The disability studies reader. New York: Routledge, pp.246-262.

Bechter, F., 2008. The deaf convert culture and its lessons for deaf theory. In: H-D. L. Bauman, ed. Open your eyes: deaf studies talking. Minneapolis: University of Minnesota Press, pp.60-79.

Bennett, S., 1990. Theatre audiences: a theory of production and reception. London: Routledge.

Brecht, B., 1964. Brecht on theatre: the development of an aesthetic. Translated by J. Willett. London: Methuen.

Conley, W., 2001. In search of the perfect sign language script: insights into the diverse writing styles of deaf playwrights. In: L. Bragg, ed. Deaf world: a historical reader and primary source book. New York: New York University Press, pp.147-161.

Conrad, R., 1979. The deaf schoolchild: language and cognitive function. New York: Harper \& Row.

Corker, M., 1998. Deaf and disabled, or deafness disabled?: Towards a human rights perspective. Buckingham: Open University Press.

Cremona, V. A., Eversmann, P., Van Maanen, H., Sauter, W. and Tulloch, J., 2004. Theatrical events: borders, dynamics, frames. Amsterdam: Rodopi.

Davis, L. J., 2008. Postdeafness. In: H-D. L. Bauman, ed. 2008. Open your eyes: deaf studies talking. Minneapolis: University of Minnesota Press, pp.314-325.

Emery, S. D., 2009. In space no one can see you waving your hands: making citizenship meaningful to Deaf worlds. Citizenship Studies, 13(1), pp.31-44.

Fischer-Lichte, E., 2014. The Concept of Performance. In: M. Arjomand and R. Masse, eds. The Routledge introduction to theatre and performance studies. Abingdon: Routledge, pp.18-45.

Fraser, N., 1990. Rethinking the public sphere: a contribution to the critique of actually existing democracy. Social Text, 25/26, pp.56-80. 
Ganz Horwitz, M., 2014. Demands and strategies of interpreting a theatrical performance into American sign language. Journal of Interpretation, 23(1), pp.1-18.

Gebron, J., 2000. Sign the speech: an introduction to theatrical interpreting. 2nd ed. Hillsboro: Butte Publications Inc.

Glasgow Film Theatre, n.d. Visual Cinema Club. [online] Available at: 〈https://glasgowfilm.org/plan-your-visit/venue-access/visiblecinema-club> [Accessed 19 April 2018].

Habermas, J., 1989. The structural transformation of the public sphere. Cambridge: Polity Press.

Hadley, B., 2014. Disability, public space performance and spectatorship: unconscious performers. Basingstoke: Palgrave Macmillan.

Harris, M., Terletski, E. and Kyle, F. E., 2017. Literacy outcomes for primary school children who are deaf and hard of hearing: a cohort comparison study. Journal of Speech Language and Hearing Research, 60(3), pp.701-711.

Inkblot Collective, 2016. [online] Available at: 〈https://www.facebook.com/inkblot.collective/〉 [Accessed 10 January 2018].

Kennedy, D., 2009. The spectator and the spectacle: audiences in modernity and postmodernity. Cambridge: Cambridge University Press.

Koller, A. ed., 2012. Transformations of the public sphere. [online] Available at: 〈http://publicsphere.ssrc.org/about/〉 [Accessed 22 January 2018].

Kuppers, P., 2013. Disability and contemporary performance: bodies on the edge. London: Routledge.

Lockwood, E. M., 2014. Effective deaf action in the deaf community in Uruguay. In: H-D. L. Bauman and J. J. Murray, eds. 2014. Deaf gain: raising the stakes for human diversity. Minneapolis: The University of Minnesota Press, pp.321-340.

McDougall, D., 2015. We are (not) rockstars: honouring the performance without overpowering it. [online] Available at: 〈http://www.terptheatre.com/not-rock-stars/〉 [Accessed 25 November 2015].

Miles, D. and Fant, L. J., 1976. Sign-language theatre and deaf theatre: new definitions and directions. Northridge, CA: California State University.

Miller, F. P., Vandome, A. F., and McBrewster, J., 2010. Medical model of disability. Saarbrücken: Alphascript Publishing.

O'Brien, D., 2013. Visual research with young d/Deaf people - an investigation of the transitional experiences of $d$ /Deaf young people 
from mainstream schools using auto-driven photo-elicitation interviews. Graduate Journal of Social Science, 10(2), pp.152-175.

Padden, C., 2008. The decline of deaf clubs in the United States: a treatise on the problem of place. In H-D. L. Bauman ed. 2008. Open your eyes: deaf studies talking. Minneapolis: University of Minnesota Press, pp.169-176.

Padden, C. and Humphries, T., 1988. Deaf in America - voices from a culture. Cambridge, MA: Harvard University Press.

Rancière, J., 2007. The emancipated spectator. Artforum International, 45(7), pp.271-280.

Reinelt, J., 2011. Rethinking the public sphere for a global age. Performance Research, 16(2), pp.16-27.

Richardson, M. (2017) Sign language interpreting in theatre: using the human body to create pictures of the human soul. TranscUlturAl - A Journal of Translation and Cultural Studies, 9(1). [online] Available at: 〈https://journals.library.ualberta.ca/tc/index.php/TC/article/view/29 265> [Accessed 23 November 2017].

Richardson, M. (2018) The sign language interpreted performance: a failure of access provision for deaf spectators. Theatre Topics, 28(1), pp.63-74.

Rocks, S., 2011. The theatre sign language interpreter and the competing visual narrative: the translation and interpretation of theatrical texts into British sign language. In: R.W. Baines, C. Marinetti, and M. Perteghella, eds. Staging and performance translation: text and theatre practice. Hampshire: Palgrave Macmillan, pp.72-86.

Rocks, S., 2015. Theatre interpreting. In: F. Pochhacker, ed. Routledge encyclopedia of intepreting studies. Abingdon: Routledge, pp.417-418.

Ruane, T., 2009. Theatresign. [online] Available at:

〈http://www.theatresign.com/〉 [Accessed: 30 November 2015].

Sacks, O., 1991. Seeing voices: a journey into the world of the deaf. London: Picador.

Sandahl, C. and Auslander, P., 2005. Introduction. In: C. Sandahl, and P. Auslander, eds. Bodies in commotion: disability and performance. Ann Arbor: The University of Michigan Press, pp.1-15.

Sauter, W., 2000. The theatrical event: dynamics of performance and perception. Iowa City: University of Iowa Press.

Solar Bear (n.d.) Best practice for creating accessible theatre for D/deaf audiences. [online] Available at: 〈http://www.solarbear.org.uk/resources/best-practice-for-accessibletheatre/> [Accessed 19 April 2018]. 
Tulloch, J., 2005. Shakespeare and Chekhov in production and reception: theatrical events and their audiences. Iowa City: University of Iowa Press.

Turner, G. H. and Pollitt, K., 2002. Community interpreting meets literary translation. The Translator, 8(1), pp.25-47.

Valentine, G. and Skelton, T., 2008. Changing spaces: the role of the internet in shaping deaf geographies. Social \& Cultural Geography, 9(5), pp.469-485.

Warner, M., 2002. Publics and counterpublics (abbreviated version). Quarterly Journal of Speech, 88(4), pp.413-25.

Weller, S. C. and Romney, A. K., 1988. Systematic data collection. London: SAGE Publications.

Woll, B., Sutton-Spence, R. and Elton, F., 2001. Multilingualism: the global approach to sign languages. In: C. Lucas, ed. The sociolinguistics of sign languages. Cambridge: Cambridge University Press, pp.8-32.

Wood, J., 1964. Introduction. In: Beaumarchais, P.-A.C.d. and Wood, J., 1964. The Barber of Seville and The Marriage of Figaro. London: Penguin Books.

Young, A. and Hunt, R., 2011. Research with d/Deaf people. London: NIHR School for Social Care Research.

Young, A. and Temple, B., 2014. Approaches to social research: the case of deaf studies. Oxford: Oxford University Press.

\section{About the authors}

MICHAEL RICHARDSON is a PhD candidate at Heriot-Watt University. $\mathrm{He}$ is researching the participation of Deaf people in theatre and has presented his work at several international conferences. He previously worked in applied theatre and musical theatre, and his book, Youth theatre, drama for life was published by Routledge in 2015.

DAVID THOMPSON is a keen theatre-goer. He has participated in every stage of Michael's $\mathrm{PhD}$ research, including its dissemination to the Deaf community. He has worked with several theatres to try to improve their service to Deaf people, and is a founder member of Alba Cats, a Scottish collective of Deaf creatives. 
Scottish Journal of Performance

Volume 5, Issue 2 
PRACTITIONER REPORT:

\section{Composing interaction: performativity in Mechanical}

TIMOTHY COOPER

DOI: 10.14439/sjop.2018.0502.03

Publication date: 30 September 2018

This paper explores the creation of Mechanical (2016), an interactive sound installation that explores the sound and physicality of old, worn and broken bicycle parts. In the paper I examine the question: what is the nature of the interaction in Mechanical? I will argue that the interaction elicits performative actions by the audience. I will contextualise this action through Sarah Rubidge's 'Performing installations' (2009). These performative actions are enabled by the specific nature of the interactive system which I will contextualise through Simon Emmerson's notion of meaningful response (2012; 2013). I will conclude that the specific nature of the interaction is characterised by the network formed by the system between audience members and the 'bikes', and the types of behaviour engaged in by the audience.

Keywords: electroacoustic music, sound-art, interactive, installation, performativity.

\section{Introduction}

In 2016 I created Mechanical, an interactive sound installation. The installation explores the sound and physicality of old, worn and broken bicycle parts. If the piece began as a way to save my Reynolds 531 Claude Butler Elite bike frame from the scrap heap, it grew into a piece where 
the interactive sonic experience became the key focus of the work.

Through examining the nature of the interactivity in Mechanical, I will argue that the work elicits performative actions by the audience. This will be contextualised through Sarah Rubidge's 'Performing Installations' (2009). These performative actions are enabled by the specific nature of the interactive system which I will contextualise through Simon Emmerson's notion of meaningful response (2012; 2013).

In the main body of the paper I will begin by giving a basic description of the installation, touching upon the set-up of the work, the nature of the audience, and the sound world of the work. I will follow this with a discussion of the nature of the interactive system describing the pertinent technical issues. The discussion will conclude with a contextualisation of the performative action of the audience.

I will discuss these issues from the point of view of the first presentation, the specific circumstances of which seemed to impact the work dramatically. The creation of the installation was supported by Cryptic, a Glasgow based company whose activity formerly focused on contemporary theatre work. Cryptic's output has transitioned to focus on sonic art that engages an audience visually as well as sonically. Their activity includes a biennial festival (SONICA-sonic art for the visually minded), their Cryptic Associates programme that 'nurtures and develops the next generation of artists' (Cryptic, 2016) and Cryptic Nights that provides a platform for emerging artists to present work. Their activity continues to support and produce performances, both in a traditional sense and in less traditional senses where artists might 'perform' a version of an installation. Mechanical was presented to an audience that holds these expectations from a Cryptic event and in a 
space regularly used by Cryptic for performances. I would suggest that this contributed to the particular character of the first presentations. In the first presentation, a relatively large number of audience members inhabited the installation at any one time (up to 40). This was a larger number than I had expected and allowed for interesting dynamics to emerge between the audience members. This dynamic contributed to audience members inhabiting the installation for longer than I expected (some audience members stayed for up to 40 minutes), which meant they could discover more about the different layers of the work than I had anticipated.

\section{Presenting Mechanical}

\section{The basic set-up}

Mechanical consists of three 'bikes' suspended on scaffolding poles (see figure 1). These are positioned in a triangle in the centre of the space. Each of the bikes has a handle attached to the crank arm, which can be used to drive the bicycle wheel. Attached to the bikes are microphones and dynamos; information is fed to a computer program in two ways; by the microphone about the sounds produced, and by a dynamo about the voltage generated when the wheel spins. 


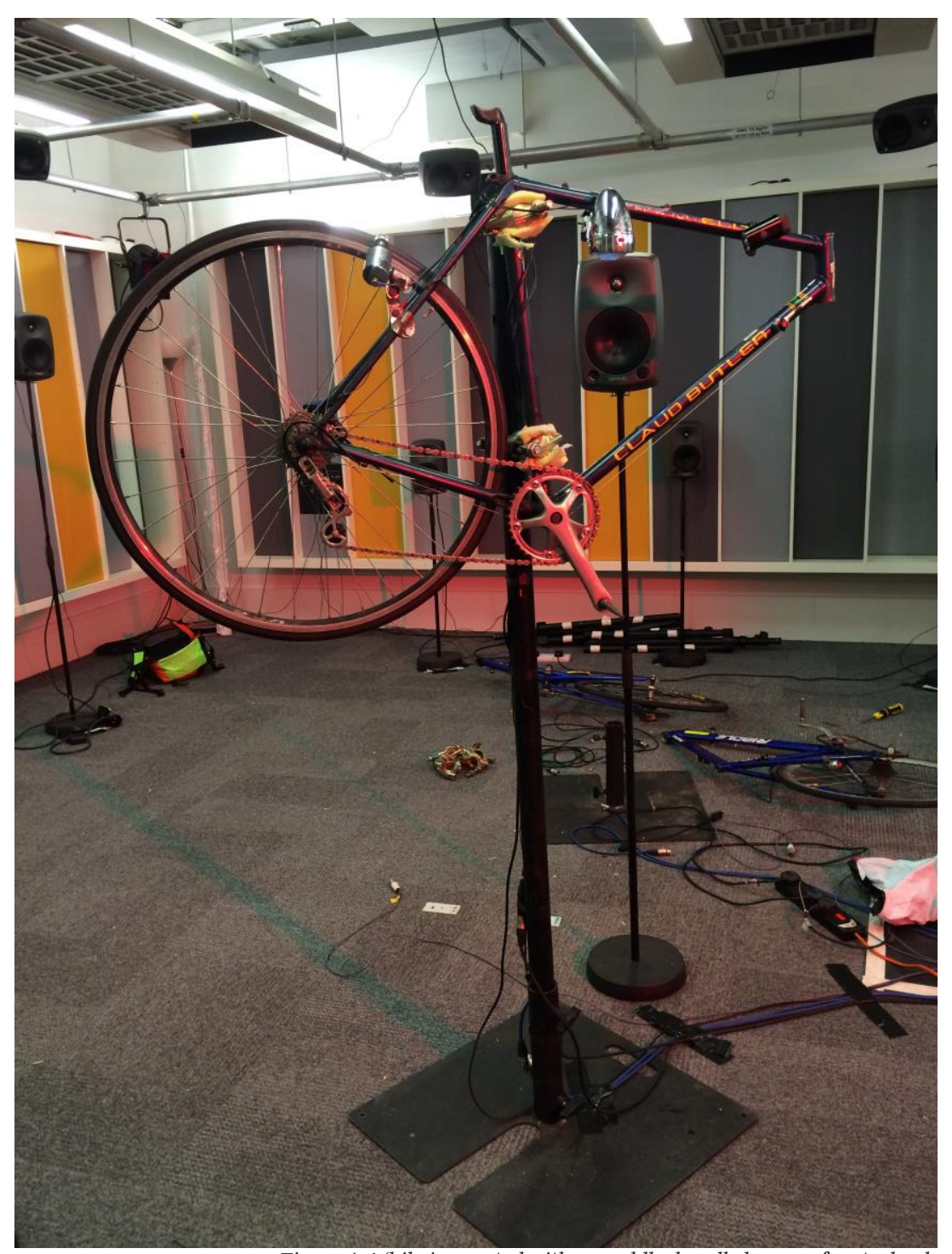

Figure 1: A 'bike' mounted with no saddle, handle bars, or front wheel. $A$ handle presented itself to the audience members.

A ring of eight loudspeakers surround the bikes and three individual loudspeakers are placed closely to each of the bikes. The loudspeaker ring plays back sounds that immerse the audience and that respond to the actions of the players (see figure 2). Overhead, two 'tweeter trees' (high frequency loudspeaker arrays) are suspended above the bikes. The 'tweeter trees' resemble the spokes of bicycle wheels (these are not shown in figure 2 to retain clarity in the image). 


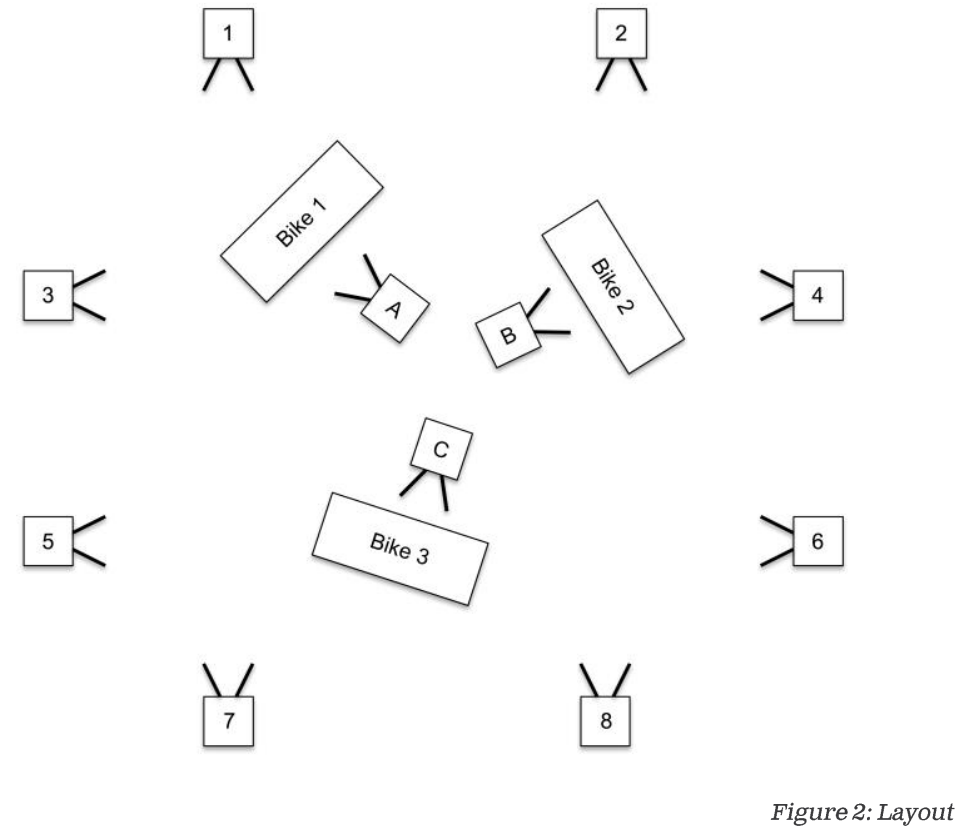

Mechanical was first presented at Cryptic Nights. The audience was invited to explore two different interactive installations following a live performance. The other interactive work was designed to be experienced by one person at a time, meaning that most of the audience moved directly into the space Mechanical inhabited.

Audience members interact with the bikes by turning the handle. The sound produced together with the voltage generated by the dynamo is analysed by a computer program that uses this information to trigger, and manipulate, pre-recorded sounds.

As the player(s) continue to interact with the bike(s), the program gives the player(s) greater control by allowing access to a new stream of sound, or by adapting the way the system responds to their input.

Mechanical is designed to be accessible to audience members who have no previous experience of the work. It is also designed with enough layers of complexity to 
encourage extended play and repeated play. On repeat visits I expect that audience members will discover deeper layers of connectivity between themselves and the sound world of the installation.

\section{Visually presenting the bikes}

Presenting the bikes as incomplete / non-functional is a sculptural decision. Whilst my focus was on the sound materials and the interactive system, it is impossible to ignore the bikes as physical objects in the installation space. The choices around mounting the bikes revolved around conceptual and practical aspects. On a practical level, the mounting needed to be sturdy enough that the participants felt 'permitted' to turn the crank vigorously, if they chose. Conceptually there were numerous options. The choice was made to mount the bikes in a visually simple way, attaching the frame securely to a black scaffolding pole and base. This emphasised the shapes of the individual bikes frames as aesthetic objects, rather than as functional (or in this case non-functioning) vehicles (figure 1).

\section{Layout of the space}

The space is laid out as in figure 2. The three players can look through their bike to see the other players. That is important when thinking about co-operative playing. Individual loudspeakers (A, B and C) are visible through the bike frame (figure 3 ) and these carry the sounds that are closely relatable to an audience member's action. A ring of eight loudspeakers, positioned above head height (numbered 1-8 in figure 2) frames the space. The materials sent to these loudspeakers create a sonic environment that immerses the audience. High frequency loudspeakers (not shown in figure 2) suspended over the audience carry the same material as the 8-channel array. However, the balance between the high array and the main array changes depending upon the level of activity in the space (this aspect 
will be expanded upon in a later section about co-operative play). When the work is dormant the level of the overhead loudspeakers is higher than the level of the main array. When the audience members turn the bike cranks, activating the work, the sounds descend into the main ring of eight loudspeakers.

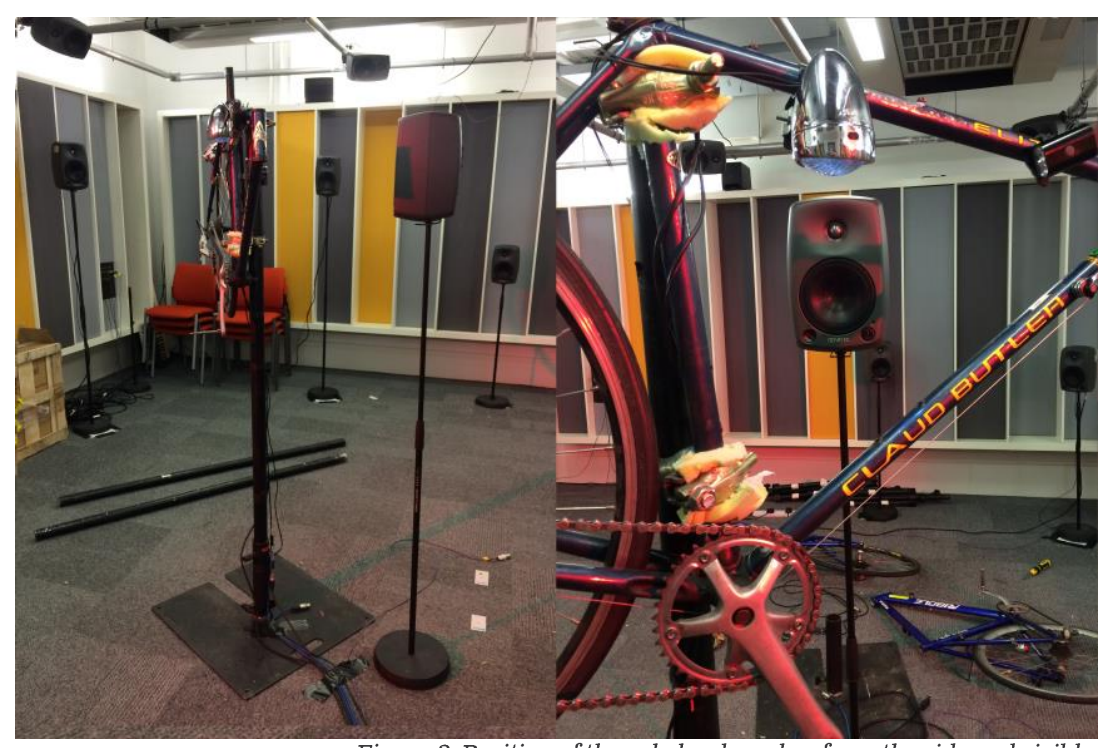

Figure 3: Position of the solo loudspeaker from the side and visible through the frame of the bike.

White and red bike lights are mounted on each bike and provide most of the light in the space. The installation space is also lit by a wash of red light from overhead.

Video 1 gives an impression of the installation experience. It is evident in the video that audience members explore the space and engage with the bikes and the audio gives a sense of the immersive sound world, using stereo playback.

https://youtu.be/f_MkogBJfaY 


\section{The audience}

In most installations one would not think of the visitors as being an 'audience'. In this work it is impossible to ignore the possibility of performance; if there are performers, who might they be performing to?

When engaging with the installation, on the surface it would seem there are two distinct ways to do this. For the purposes of this paper I will call these:

1. Player(s)-an audience member or members that are actively engaged in interacting with a bike physically and sonically.

2. Listener / onlooker(s)-an audience member or members that are exploring the space visually and sonically.

It is important to consider to what extent the player(s) consciously perform outwardly and to what extent that is encouraged by the work. From my perspective, I am uncomfortable with the idea that the work would require or encourage the player(s) to perform outwardly to the onlookers. Mechanical was created to encourage play and playfulness through sonic interaction. It would be an unfair expectation to assume that all audience members would be comfortable performing. In this respect, the player(s) are performing on the bikes rather than performing to the audience. However, if players choose to think of themselves as performers and they are performing to the other audience members, I am comfortable with them selfidentifying in this way.

Where the roles become more complex is when we consider how active the participation of the listener / onlooker(s) may be. From video 1, it is very clear that the audience is 
exploring the space, finding different vantage points from which to view / listen to the work. This is a more active role than it would seem at first.

In the context of the first presentation it is important to think about the way the audience members negotiated the space. There were $40+$ present and only three bikes. From my perspective I observed:

- Turn taking-the listener / onlookers seemed to wait patiently listening to and observing the interactions of the player(s).

- Sharing-there were moments where several players shared the same bikes, perhaps with one person making suggestions, or through one person turning the crank and the other changing gears.

- Exploring-most audience members spent most of their time listening / onlooking. Many of them seemed to explore the space thoroughly, perhaps moving from speaker to speaker, to listen from different parts of the space and take in different perspectives. Some audience members moved to different parts of the space from outside the ring of speakers to the space in between the bikes at the centre of the installation.

\section{Sound layers}

Within the work it is possible to hear up to 10 layers of sound. Six of these are directly interacted with by the player(s). 


\begin{tabular}{|c|c|}
\hline Layer & Bikes \\
\hline $\begin{array}{l}\text { Amplified Bike } \\
\text { Sounds } \\
\text { (3 layers) }\end{array}$ & $\begin{array}{l}\text { Each bike is amplified by a miniature condenser } \\
\text { microphone, which heightens the acoustic sound } \\
\text { of the bike. It also 'places' the sound of the bikes } \\
\text { within the solo loudspeaker. } \\
\text { Each bike also has a contact mic attached. These } \\
\text { microphones have quite an unnatural sound and } \\
\text { are not used throughout the work. They are only } \\
\text { used when the player turns the crank of their bike } \\
\text { forwards. }\end{array}$ \\
\hline $\begin{array}{l}\text { Solo Sounds } \\
\text { (3 layers) }\end{array}$ & $\begin{array}{l}\text { Each bike has access to a layer of solo sounds that } \\
\text { are projected only in their solo loudspeakers. The } \\
\text { relationship between the physical action and the } \\
\text { sonic result is extremely clear. }\end{array}$ \\
\hline $\begin{array}{l}\text { Textural } \\
\text { Gestures } \\
\text { (3 layers) }\end{array}$ & $\begin{array}{l}\text { Each bike has access to sounds with one of two } \\
\text { spatial identities: } \\
\text { 1. Sounds that fully occupy the 8-channel } \\
\text { array, with very little spatial movement. } \\
\text { 2. Sounds that are spatially active and } \\
\text { move (with spatial motions related to the } \\
\text { bicycles) around the 8-channel array. } \\
\text { With this layer, the relationship between the } \\
\text { physical action and the sonic result is more } \\
\text { disguised because this is shared amongst the } \\
\text { bikes. }\end{array}$ \\
\hline $\begin{array}{l}\text { Supporting } \\
\text { Texture } \\
\text { (1 layer) }\end{array}$ & $\begin{array}{l}\text { This layer provides a background for the other } \\
\text { sounds to be layered upon. Generally, this layer is } \\
\text { gesturally quite static and is usually quite specific } \\
\text { spectrally (mostly high, mid or low frequency) to } \\
\text { provide space for the other sounds. }\end{array}$ \\
\hline
\end{tabular}


All of the sounds in the work are derived from recordings I made of the Claude Butler bike and from the Time Trial in the 2017 British National Cycling Road Race.

The layer of solo sounds is both physically relatable and sonically relatable. They are reminiscent of bicycle chain sounds; these sounds create a bridge between the amplified sound of the bike and the other layers of sounds. One would not immediately relate the textural or supporting sounds to the bikes; however, through this careful orchestration and distribution of materials, these sonic relationships become apparent when the audience spends time within the installation.

\section{Interactivity}

In this section I will use Simon Emmerson's notion of meaningful response to contextualise the thinking that informed the design of the interactive system. In a series of articles, (1994; 1998; 2012; 2013), Emmerson has progressed our understanding of interactivity and liveness between performers and electroacoustic music. Initially, Emmerson described the experience of interactivity from the perspective of the composer and the audience (Emmerson, $1994 ; 1998)$. He has moved this thinking on to place the onus on the relationship between the performer and the electroacoustic materials.

When we discussed cause and interactivity... we did not specify who was perceiving (or trying to work out) the cause. It is surely the performer who must first and foremost feel a true response from a live electronic system (Emmerson, 2012, p.15). 
Emmerson describes 'The definition of appropriate and meaningful' relationships crossing boundaries 'from the technical cause to musical affect... The performer is key here and we've tended to neglect their feelings in many of our discussions' (ibid.).

Emmerson is discussing a trained musician performing with electroacoustic resources (whether these are live / real-time or fixed). The expert player(s) described are

...used to highly consistent cause-effect chains... $\mathrm{s} /$ he is particularly acute at listening and generating intricate and multiple feedback loops: listen > modify action > modify sound > listen... though usually not unconscious, often being the result of many hours of practice (Emmerson, 2013, p.5).

Here, Emmerson is describing the necessary conditions for meaningful response to occur. The modification of action in response to something the performer hears is critical in this process.

He also argues that it is not through the technical causes (whether these are programmed or composed) but through the experience of the performer that meaningful response manifests. Regardless of any programmed or composed relationships, the performer must feel that they are connected to the electroacoustic material. The relationship must be understandable and relatable. Critically, it must be a two-way relationship where the performers feel they can cause a response from the system and, in turn, feel prompted to respond to the system. Emmerson is arguing that relationships must be forged in the truest sense with perceived agency from both sides of the system. From this point of view, Emmerson is also suggesting that it does not 
make any difference whether the response is made by live manipulation of the sound or through pre-composing material.

In Mechanical, the players are different, as most of them will have no (or little) prior experience of playing this installation. Many of us will have experience of bicycles, but most of us will not have turned the drive chain of a bike by hand; in order to create these meaningful relationships, Mechanical is sensitive to this. I designed the system so that players can discover ways to play the bikes relatively intuitively. Instructions (perhaps akin to fingering charts for woodwind or brass instruments) are not provided; however, the 'instrument' itself is designed to guide the player, by rewarding certain kinds of activity. In order for this to happen, the system needs to provide the right kind of feedback for the player. It is through the design of the bikes and the invitation to play, and to continue playing, that the notion of meaningful response is enacted.

\section{Instrument design}

The interactive system is a network between the player(s) and the sounds produced. This is a technical system where the full potential of the installation will reveal itself through co-operative play. However, it extends out to the players as their input will be guided by the meaningful relationships they forge with their bikes and the impact that the input of the other player(s) will also have. Aspects of the network reveal themselves to individual players through their individual interactions, whereas other aspects only fully reveal themselves through co-operative playing.

Figure 4 shows how the information is transferred through the network relating to individual play: 
1. The player physically turns the crank of the bike (shown by the black arrows).

2. The energy produced (sonically and electrically) is transmitted to the interactive system (shown by the yellow arrows).

3. The interactive system analyses this information and makes appropriate decisions about which sounds to produce.

4. The sounds are sent to the loudspeakers which project them to the players (shown by the blue arrows).

This transfer of information relies on the system feeding back information sonically to the player(s), who adjust their action physically, creating a different sonic result.

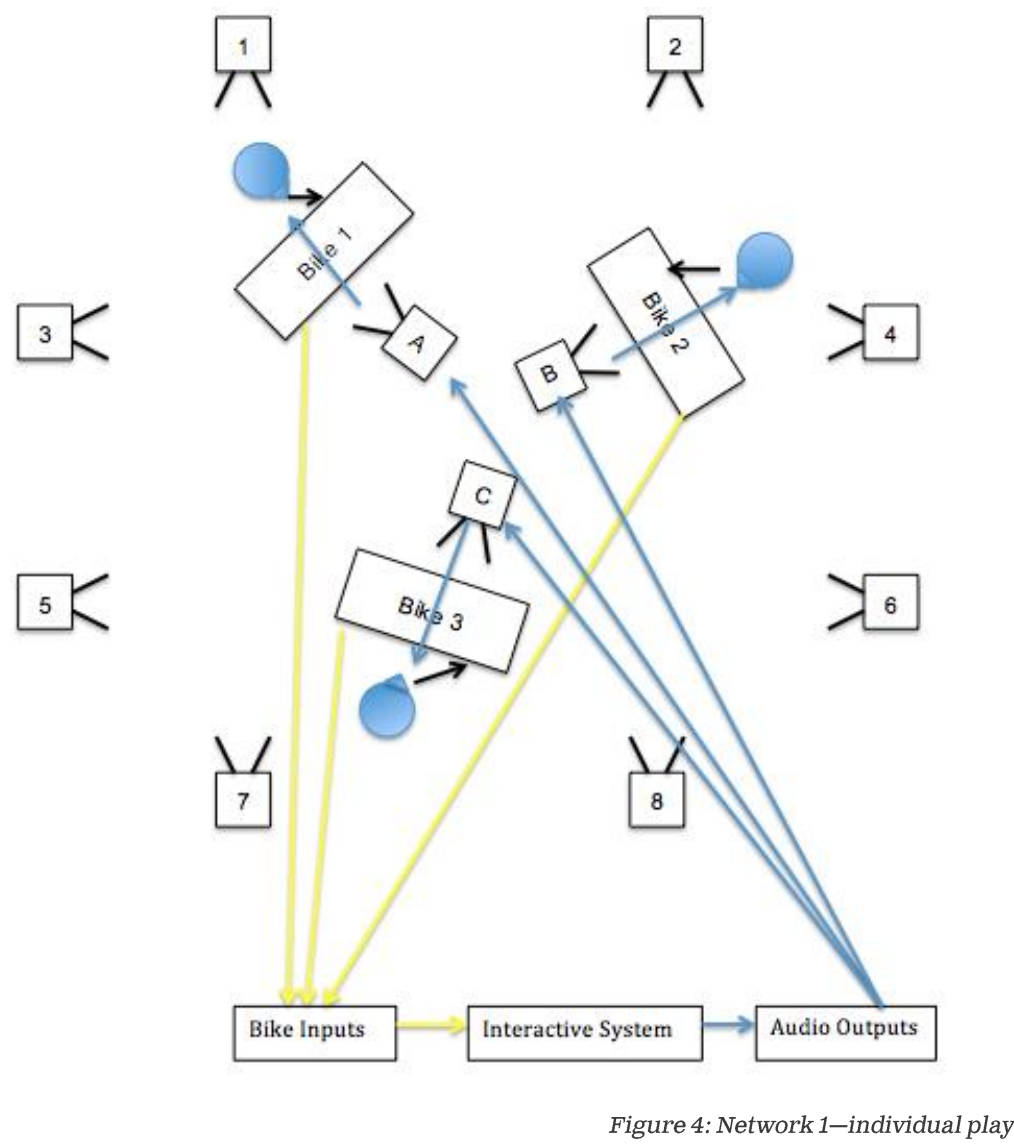

This becomes even more complex in figure 5 when the action and resulting sound produced by the player(s) is 
taken into account by the other players, together with the overall sound of the 8-channel system. Their behaviour in the first presentation began to change in order to adapt to the sound world evolving around them (shown by the green lines).

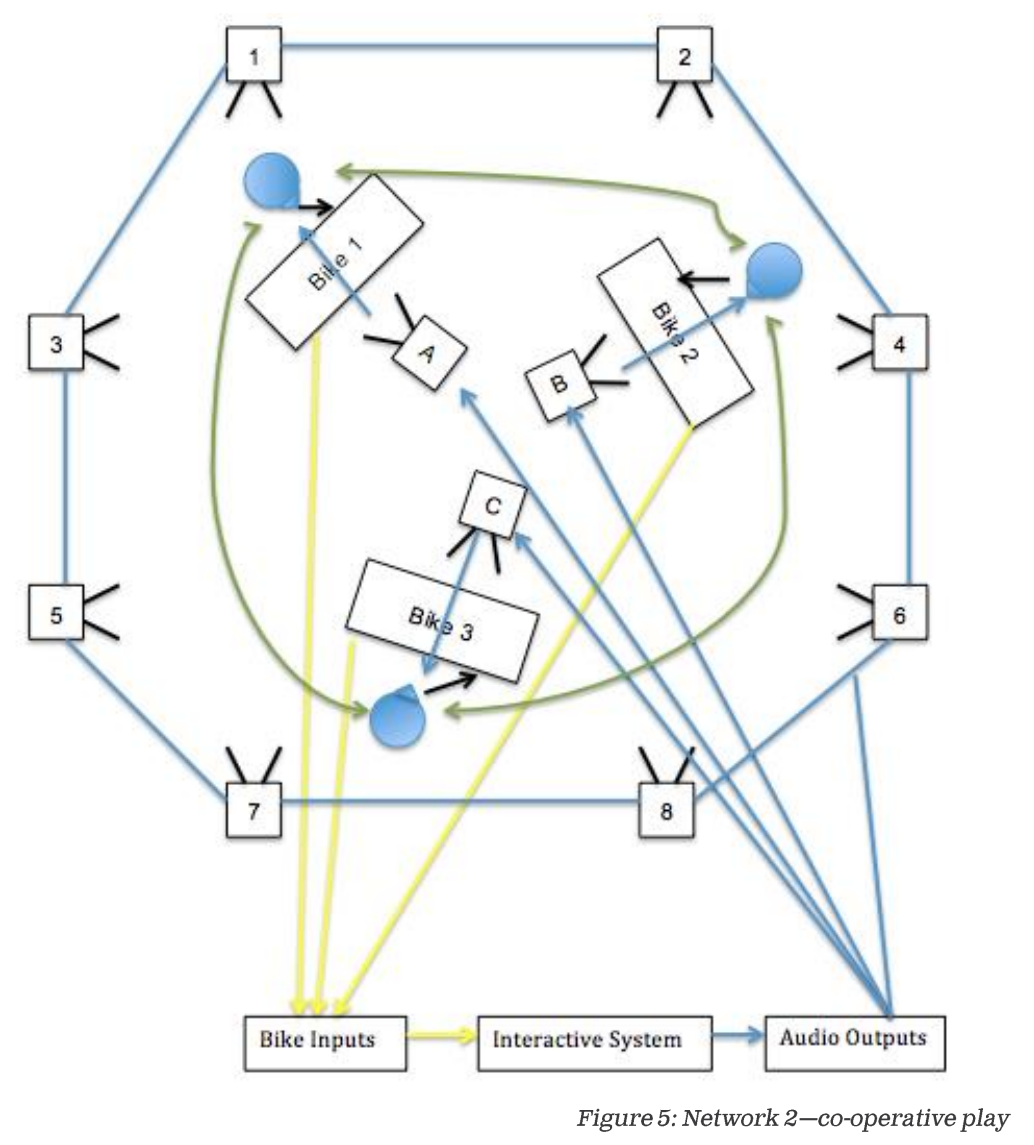

\section{Individual play}

In early work on the piece I thought about the notion of the player controlling the sounds. This led to ideas surrounding gaming and gameplay as potential models for developing the system. As the compositional process progressed it became clear that the bike's interface had moved beyond the idea that the player was, or even could be in control. The complexity of the bike as a tactile object became increasingly important through the compositional process. The sensation of turning the crank is not nearly as simple as it might seem. The different sensations one engages in when turning the crank forwards or backwards reveals 
different kinds of energy required to sustain the motion of the bicycle mechanics. This is reflected in the types of sounds accessed by the player(s). When winding backwards the potential dynamic, timbral and pitch range of the sounds produced are more limited than when winding forwards. The audible result here articulates the difference in the tactile sensation.

The complexity of the physical interface created significant issues when designing the interactive system. Testing early drafts of the system on 'audiences' resulted in dramatically re-imagining the nature of this network. The test program did not create meaningful relationships between the players and the bikes. It failed to meet Emmerson's condition that meaningful response must be felt first and foremost by the player (Emmerson, 2013). The sounds were too complex and layered for the listener to be able to relate their actions to the resulting sound. There were several factors here; the original system:

1. Was always sonically active. The idea was that the player influenced a stream of sound that already existed, rather than their action generating sounds that weren't already present.

2. Mapped 'control data' onto many parameters, which led to a level of complexity that was extremely hard to follow. Different layers had significantly different mappings (one sound might be pitch shifted up as more energy is put into the system whilst another's pitch would get lower).

3. Used two loudspeakers with each bike; however, the lack of specific localisation meant that the player found it hard to track the impact of their action upon the installation because they didn't know the 'location' of their sound(s). Most instruments are very easy to locate sonically and it seemed to make 
sense to use just one loudspeaker to really place the sound within an individual loudspeaker.

The invitation to play and the invitation to continue to play

The issues raised during testing led me to re-evaluate what aspects should define the piece. This led me to compose, more carefully, two specific and critical moments in the interaction between player and bikes:

1. The invitation to play.

The invitation to play is part visual and part sonic. There is no pedal attached to the crank arm. The use of a handle is a conscious, visual attempt to encourage an audience member to turn the crank and therefore 'play' a bike (figure $6)$.

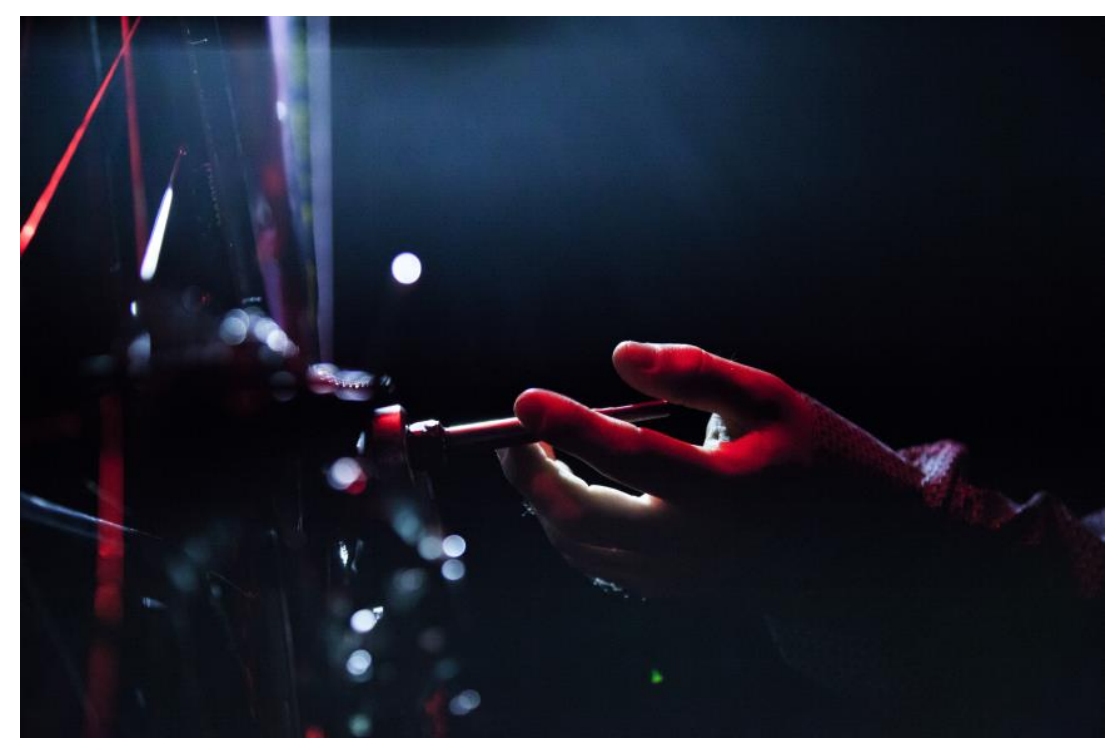

Figure 6: Audience member reaching for a handle. Photograph courtesy of Robert McFadzean. 
Localising the individual bike sounds in mono loudspeakers contributed greatly to the forging of a relationship between the player and their bike. Amplifying the acoustic sound of the bike to a level that draws the player's attention forwards, towards that loudspeaker, helps the player to relate to the sounds projected by their solo speaker.

The invitation to play is reinforced by a clear one-to-one relationship between the player and the bike. As soon as a player begins to turn the crank, simple, relatable sounds are produced. This moment is heightened by triggered sounds that articulate the initial interaction, giving the player confidence that their action produced the resulting sounds.

2. The invitation to continue to play.

The invitation to continue to play is made by the system responding to the action of a player. There are two aspects to consider here. Firstly, the natural variation in the player's action will result in slightly different responses from the system, even when they perform exactly the same action (of course, performing precisely the same action is impossible). Simon Waters argues that classical music instruments 'are increasingly designed to have predictable linear behaviours' (Waters, 2013, p.123). In this context, he is discussing instruments designed for more traditional music making where (relatively) exact repeatability is desired. This is not possible in Mechanical because of the complexity of the bike as an interface.

Secondly, the system is designed to progress with the player. As the player continues to play, the system's response is programmed to change. Each time a player stops turning the crank momentarily, the system will 'progress', giving the player access to further possibilities. 
At each point the system 'progresses' it makes a choice either to:

1. Give the player a new sound to play in addition to the sound(s) they already have access to.

2. Change the way the data is mapped on the sound in one of two ways:

a. Change the mapping of a parameter they are already engaged with.

b. Map the data onto an additional parameter.

At each pause between actions, the system makes the same choices: to add sounds or to progress a sound. Each bike can access to up to five sounds. The nature of the system is such that if a player plays for long enough they will also get full access to all five sounds, but that they will almost never have precisely the same control over these sound types. Figure 7 expresses progression routes visually and video 2 shows this happening with a solo player and with two players.

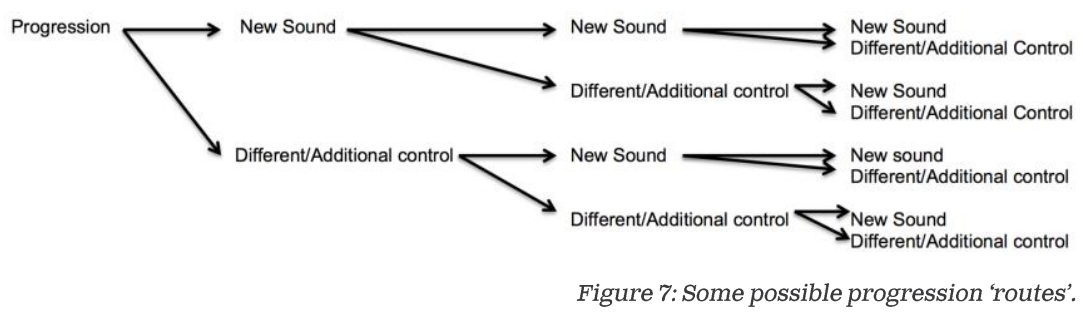

https://youtu.be/WPhu8h6UBfo

\section{Co-operative play}

Co-operative play affects the 8-channel sonic environment. The individual data streams are mapped to: 
1. The overall volume of the multichannel system. When the system is dormant the overall sound of the installation is relatively low. When it is activated through one or more bikes being played the overall volume increases. Each bike has access to 8-channel textures that are projected around the audience. These generally exhibit much higher energy than the solo sounds or are very specific spectrally (like a very low rumble). It is expected not that the player would be immediately aware of their relationship with these sounds, but that through continued play their relationship with these sounds becomes apparent. At this point the relationship that they forge with these sounds will affect the way the player engages with the system. As they become aware of additional layers of sound, or the energy they input is mapped onto more parameters, they can play in a more conscious way not only with the simple one-to-one mappings but also with the more apparently complex sounds.

2. The way the sounds occupy the space. When the players co-operatively put more energy into the system the sounds descend into the main ring of eight loudspeakers. This makes the sounds more immersive as they are no longer spatialised principally above the audience. Another aspect to this is the way the sounds occupy the 8-channel space. If only one player is putting lots of energy into the system then the 8-channel materials will be loudest in their part of the space. In order for the space to be fully activated then all three players need to put lots of energy into the system (shown in figure 8).

3. Spectral density. With less energy in the system the multi-channel sounds are filtered to make the overall sound brighter, and therefore lighter in texture. When more energy is input the filter is automated to increase the low-mid and low frequency sound, which makes the texture heavier, more immersive and more 'environmental'. 


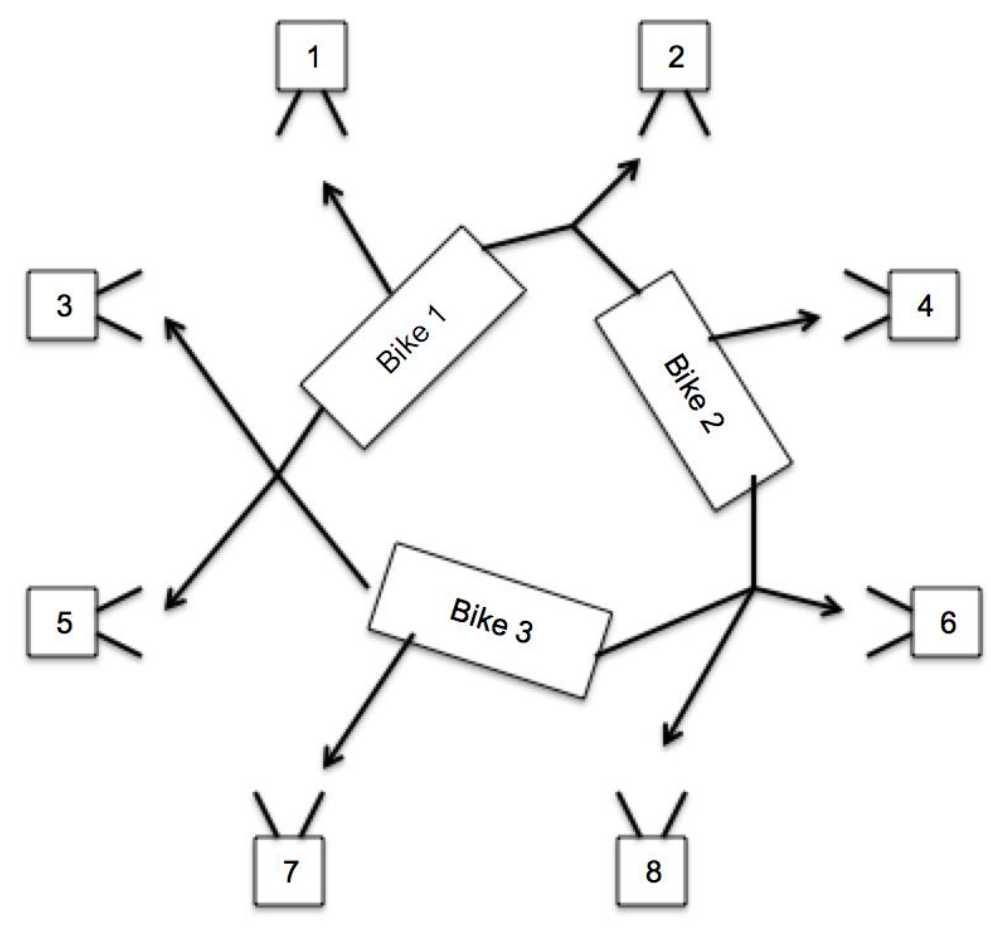

Figure 8 shows that channels 1,4 and 7 are directly controlled by the bike that is closest and channels 2, 3, 5, 6 and 8 are controlled co-operatively by the two bikes

that are closest. If one bike is being played then the speakers around it will become louder. In order for the full potential of the system to be realised all three players need to input high energy.

\section{Performativity}

In this part of this paper I will set out the specific conditions of the work that define the audience action as performative, based on three key aspects of the work.

1. Visitors' Behaviour.

Sarah Rubidge argues that '...performative installations, which acknowledge the philosophical implications of the term performative frequently, reveal themselves and their content... through the visitor's behaviour' (Rubidge, 2009, p.366). This is a critical aspect in Mechanical. Without the performative action of the audience the work will remain 
dormant, and it is through this action that the sounds that form the fabric of the work itself are produced.

2. Improvisation, not restored behaviour.

Rubidge, referencing J.L. Austin, argues that performative acts bring 'a new state of affairs into being' (Rubidge, 2009). This is an important part of the nature of Mechanical. Through engaging with the installation, the audience articulates the installation space with sounds with which they are in a direct relationship. They are, through their action, bringing a new state of affairs into being because of the nature of this relationship where the interactive system responds to the behaviour of the audience. This kind of activity is by definition a kind of improvisation that Rubidge argues is a key condition for an act to be performative.

Richard Schechner discusses the notion of restored behaviours. He describes this as 'actions that are not-forthe-first time; that are prepared or rehearsed' (Schechner, 2013, p.29). He argues that all behaviours are restored in the sense that we are never performing an action for the first time. All actions are at the very least learnt from observing the behaviour of another. However, he goes on to discuss the particular nature of restored behaviours in a theatrical context. In contemporary performance it is common for theatrical performances not to explore scripted narratives, but for the artist to present a heightened version of their own behaviour. In this area of artistic work they often make work that highlights ordinary behaviours and activities and presents them in a way that becomes performance, rather than being a traditional performance. This is significantly different to an actor learning a part and relates much more strongly to Mechanical in the way the work behaves. In this context a performer may be concerned with 'doing not with meaning. [S/he] does not start with an attempt to represent 
or signify. [S/he] acts rather than acting' (Garoian quoted in Rubidge, 2009, p.366).

In applying this thinking to Mechanical, I would argue that the behaviour of the audience cannot be restored in the traditional sense of performing a pre-existing work that is re-presented to the other audience members. The audience is confronted with a work that continually adapts to their behaviour, provoking them to continue their engagement and presenting them with constantly changing possibilities.

3. No performance ritual.

Certain events are performances and other events less so. There are limits to what "is" performance... Something "is" a performance when historical and social context, convention, usage, and tradition say it is... (Schechner, 2013, p.38).

In no sense does Mechanical engage with performance ritual. The ordinary boundaries between performer and audience are dissolved, as the audience members become active participants in the work. The players are not performing, they are being playful and explorative with the interactive system.

\section{Conclusion}

It is through the interactive network that the possibility for performative action emerges. The term performative was not central to the creation of the work, but provides a useful lens through which to view the activity of the audience in the installation. Moving the work beyond the notion of 'control' was extremely important in terms of forming meaningful relationships between the player(s) and the bike(s). 
That the installation rewards extended play is critical to the success of this work in the context of the first presentation. Without the multi-layered network I have outlined above, which relies on the visitors' action, Mechanical could not engage an audience for an extended period and therefore would not elicit performative action from the audience.

Whilst I have focused on the particular circumstances of the first presentation, I would like to contrast this with the setting of the second presentation during BEAST FEaST 2017 at Birmingham University. In this second presentation, the work was open for longer periods of time and fewer people entered the work at one time. This seemed to affect the amount of time that audience members spent in the installation. As they did not have to navigate the space waiting to take turns on the bikes, they were unable to watch and listen to the actions of other players. It seemed to me that the level of engagement was much closer to what I had expected. I had anticipated when creating the work that audience members would play with one or two of the bikes for relatively short periods (1-3 minutes and staying in the work for 5-10 minutes) and would access some of the complexity of the work but not access or understand the more abstracted layers.

This suggests that, at its richest, the nature of the interaction in Mechanical is performative, and that the number of audience members engaging with the installation has a dramatic effect on the work. In the presentation at Cryptic Nights, it was clear that because the audience played for extended periods of time, the deeper layers of the interactive system became more apparent. This allowed the players to create meaningful relationships between themselves and the sounds they produced, but also to create meaningful relationships with the other players. It is through extended play (improvisation, experimentation, collaboration)-and not performing outwardly towards the 
'audience'-that the nature of the interactive system reveals itself.

\section{Acknowledgements}

I would like to acknowledge the kind support of Cryptic who supported a residency period at Cove Park which was invaluable for the creation of the work. I would also like to thank Willy Bain from Bicycle Repair for his work on the bikes, Jason Lim for work done on the interactive system, and my kind test audience members (too many to name) for helping me to shape the final version of the work. I'd also like to thank colleague Steve Macluskie from the School of Drama, Dance, Production and Film at the Royal Conservatoire for his help in finding a way to suspend the bikes that was visually striking and suitably sturdy.

Finally, I would like to thank my PhD supervisors Professor Alistair MacDonald and Dr Diana Salazar for their invaluable guidance through the creation of the work.

\section{References}

Cryptic., 2016. Associate Artists. [online] Available at: 〈http://www.cryptic.org.uk/cryptic-associates/〉 [Accessed 1 March 2017].

Emmerson, S., 1994. 'Live' versus 'real-time'. Contemporary Music Review, 10(2), pp.95-101.

Emmerson, S., 1998. Acoustic/electroacoustic: the relationship with instruments. Journal of New Music Research, 27(1-2), pp.146-164.

Emmerson, S., 2012. Location - dislocation - relocation ('Where is live electronic music?'). In: Proceedings of the IV Seminar - Music Science Technology: Frontiers and Ruptures. São Paulo (Brazil), pp.7-16.

Emmerson, S., 2013. Rebalancing the discussion on interactivity. In: Proceedings of the Electroacoustic Music Studies Network Conference. Electroacoustic Music in the Context of Interactive Approaches and Networks. Lisbon.

Rubidge, S., 2009. Performing installations. In: Contemporary Choreography: A Critical Reader. London: Routledge, pp.362-378. 
Schechner, R., 2013. Performance studies: an introduction. 3rd ed. London: Routledge.

Waters, S., 2013. Touching at a distance: resistance, tactility, proxemics and the development of a hybrid virtual / physical performance system. Contemporary Music Review, 32(2-03), pp.119-134.

\section{About the author}

TIMOTHY COOPER is a composer and performer of electroacoustic music. In his music he explores new contexts for the sounds he works with. He uses microphones as sonic microscopes, and loudspeakers to amplify and heighten the qualities of the sounds he records. Recent projects include the site-responsive installation Tide Times made with Laura Bissell, and Breathing Space for tuba and electronics composed for Danielle Price.

Tim is a PhD candidate at the Royal Conservatoire of Scotland, supervised by Professor Alistair MacDonald and Dr Diana Salazar. He lectures at the Royal Conservatoire of Scotland and at Edinburgh College. 
PRACTITIONER REPORT:

\title{
I Gladly Strained My Eyes to Follow You: a guided tour of Pollok House
}

\author{
SHAUNA MCMULLAN
}

DOI: 10.14439/sjop.2018.0502.04

Publication date: 30 September 2018

I Gladly Strained My Eyes to Follow You took the form of a guided tour of Pollok House focusing on a selection of portraits of women from the house's historically significant collection of art and artefacts. The tours, led by Pollok House volunteers and scheduled at 2pm daily between 20 April and 7 May, were included in the exhibition Cabinet Interventions, part of Glasgow International 2018. Acknowledging the absence of information surrounding the women portrayed in the House, the artist invited writers, academics, fellow artists, and Pollok House staff to respond to individual portraits. Their reflections, thoughts, provocations and questions make up the content of this artwork.

Including a selection of texts specially written for the tour, this paper will contextualise and describe the project, setting it against the wider frames of reference that fed into and supported its development.

Keywords: collective practice, feminism, socially engaged, art, text. 
Scottish Journal of Performance

Volume 5, Issue 2

\section{Entrance hall}

Unknown lady

Dates unknown

Karen Cornfield, House Manager, Pollok House, National Trust for Scotland

Is that a fly on her nose?

It's not meant to be there.

There's meant to be a story,

The person behind the face.

This portrait of a woman was painted by a man. We know about him, not about her.

'He had a name and was born on a date. He came from a country and was born in a place. He painted things that were typical of the time. He went to a city and another country. His work is exhibited among the work of other men. His most famous work is a painting'.

(But, not this one.)

When was she born and where did she live?

Where did she travel and what did she see?

Where can we see her life's work?

What was her passion?

What did she love?

Separated from her story, 
Captured in a frame,

Hung upon a wall,

To be remembered without a name.

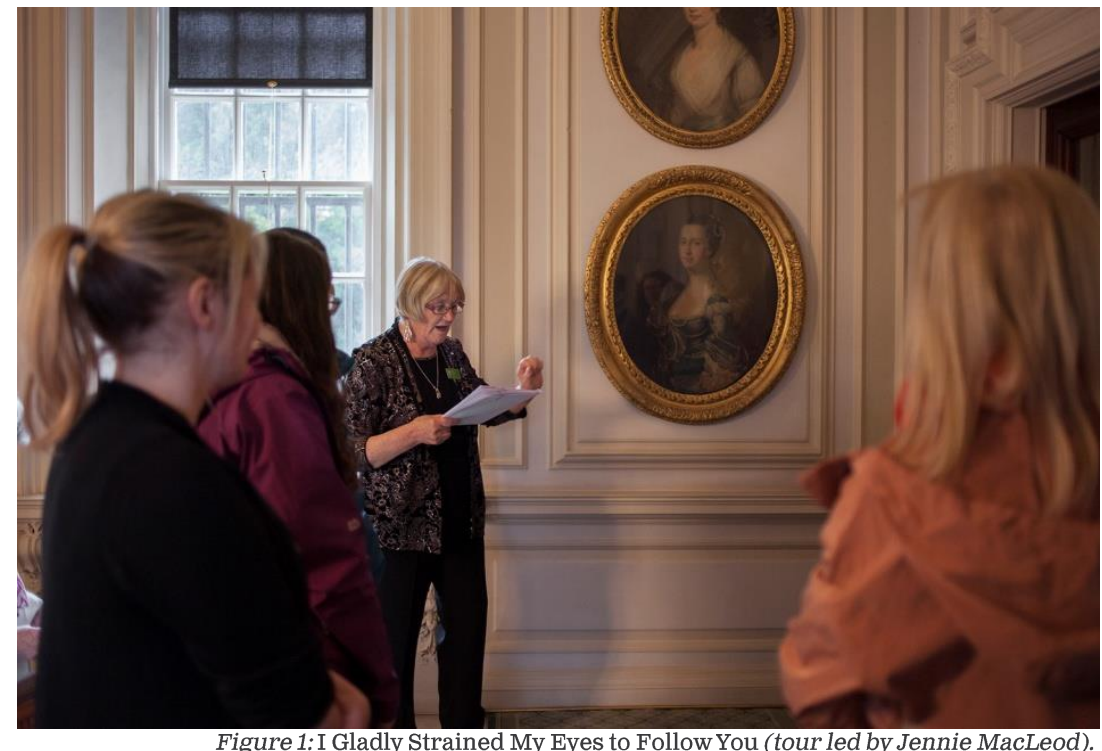

Figure 1: I Gladly Strained My Eyes to Follow You (tour led by Jennie MacLeod).

Photo: Tine Bek

Shauna McMullan: Pollok House is a stately home set in Pollok Country Park on the outskirts of Glasgow, managed by the National Trust for Scotland. The Maxwell family lived for six centuries on the site, but the main part of the present house was built in the mid-eighteenth century. The House is best known for its extensive collection of Spanish art, and it is purported to be the place (the Cedar Room to be exact), where the National Trust for Scotland was founded in 1931 by Sir John Stirling Maxwell, former owner of Pollok House. According to Sir John:

The National Trust for Scotland serves the nation as a cabinet into which it can put some of its valuable things, where they will be perfectly safe for all time, and where they are open to be seen 
and enjoyed by everyone (National Trust for Scotland, 2018).

Following an artist residency and extended period of research based in Pollok House (which was part of the research project and exhibition Cabinet Interventions ${ }^{1}$ ), I wanted to think about what art and artefacts a contemporary 'national cabinet' might contain. How could the history layered within the 'cabinet' that is Pollok House inform the development and articulation of a new body of artworks? How might we understand the value and validity of a contemporary artwork in relation to the historical collection? Was this cabinet flexible enough to accommodate the immaterial as well as the material? These are ideas and questions Rebecca Solnit touches upon in $A$ book of migrations: 'I have tried to define a place as a stable location where unstable forces converge ... whatever leads you to a place, when you get there other things lead you elsewhere on earth and in time' (Solnit, 1997, p.xiv).

\section{Main corridor}

Anne of Austria

$1549-1580$

Dr. Victoria Horne, art historian

The Spanish court painter Alonso Sánchez Coello completed this portrait of Anne of Austria in c.1570, following her marriage to King Philip II of Spain. The subject's aristocratically pale face is particularly striking against the dark, sumptuous fabric of her robes. The face is full and unlined with youthful pink blooms along the cheekbones. Bolstered by an unyielding ruff her face appears soft, nearly translucent. It implies the feminine virtues of serenity and poise. The young queen gazes out through deep hooded eyes 
and, although impassive, good humour is suggested in her expression.

Historical records tend to emphasise three things about Anne: her charm, her fecundity, and her skill with a needle. These characteristics were fundamental to an early modern feminine ideal. This was an era in which women's bodies were used as political instruments to preserve and strengthen the power of a European ruling class as it generated vast colonial expansions. In this marriage economy, women were considered vessels for producing heirs and consolidating noble alliances. Anne's fertility is thus reinforced through the gestures of the portrait, in which her left un-gloved hand appears to cradle her lower abdomen, while the flawless white pearl dangling from her headpiece symbolises the young woman's purity.

The Habsburgs consolidated their dynasty through intermarriage (Anne's husband, Philip, was also her uncle). Historians now agree that this practice led to serious health issues and the eventual termination of the line. Of Anne and Philip's five children, only one survived until adulthood and succeeded his father as Philip III of Spain.

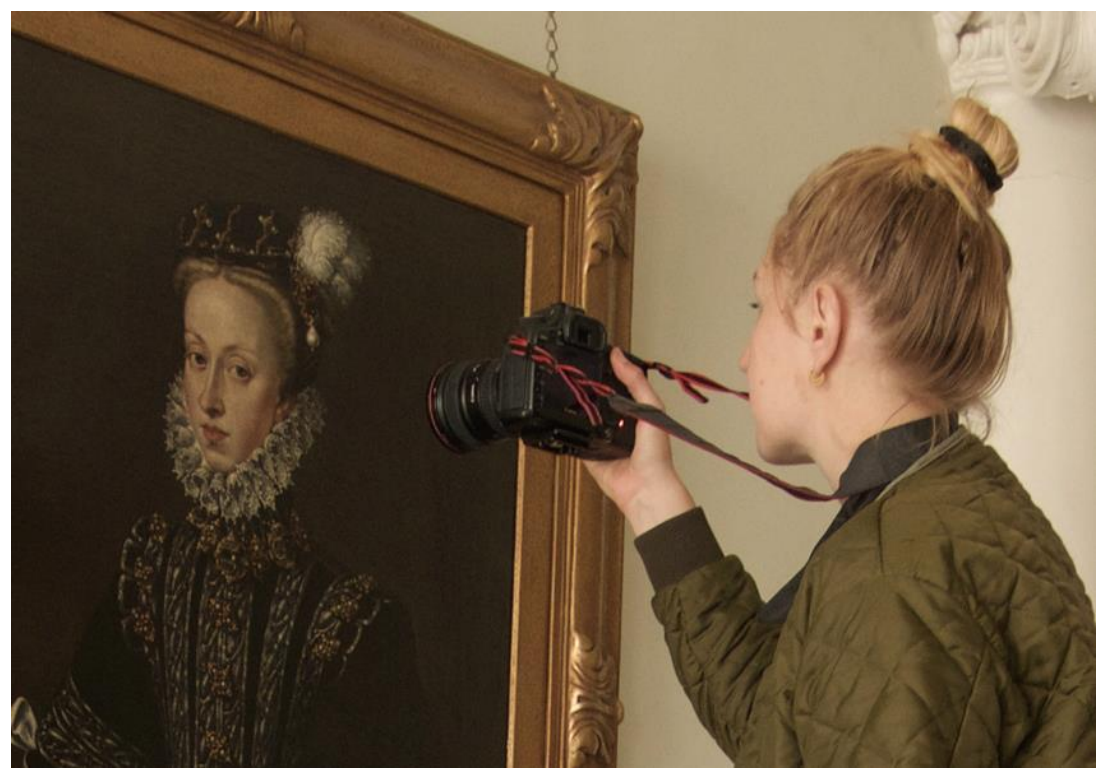

Figure 2: I Gladly Strained My Eyes to Follow You (Tine Bek / Anne of Austria). Photo: Shauna McMullan. 
SM: In total, I counted 52 portraits of women within the walls of Pollok House. Empresses, queens, courtesans, duchesses, countesses, baronesses, saints and women whose lives we know little and nothing about. They span 2,000 years from Mary Magdalene (c. AD 100) to the present day Ruth Maxwell Macdonald, who with her family still retain residency in the upper floor of the building. The women portrayed in the rooms and corridors of Pollok House lived their lives the length and breadth of Europe (in its different manifestations): Bohemia, Bavaria, Hungary, Austria, Poland, Portugal, Spain, Sweden, Italy, France, Scotland and England. Thirty-nine have names, thirteen remain lost to history. Very little has been written about the majority of them, and in what has, they have been subsumed into the narratives spun around their spouses, fathers, patrons and brothers. In the majority of cases, more is known of the painter than the subject.

Confronted with the enforced absence of women's achievements from official histories, the collective struggle has been to locate those missing voices. Feminist researchers have therefore described their enquiries as taking place in the gaps, blank pages, margins and footnotes of authorized chronicles (Horne, 2016).

\section{Business room}

Ann Christian Stirling Maxwell

$1871-1937$

Sam Ainsley, artist

Women who read are dangerous, are they not? Can you guess from my gentle, solemn, well-bred face what it is that I am reading? Well, you will not guess, for it is Mary Wollstonecraft's Vindication of the rights of women. She 
believed women must be educated equally with the men. The book was published one hundred years ago when she was 33 , the same age I am now, but she died aged only 38 after giving birth to the woman who wrote Frankenstein, Mary Shelley.

The man painting this portrait does not know what I am reading and hasn't asked; my husband will not be interested.

I think I also have a book in me, I really do; but even now, I have to write in secret. I am not taken seriously as a potential writer, I am even mocked by my family when I try to discuss the ideas that whirl around my mind; there is no encouragement to begin, let alone to continue. I am aware I live a privileged life and I try to hide my frustrations with the boredom, the endless visits, the tea and cakes, I truly do. Does my sadness show? I hope not.

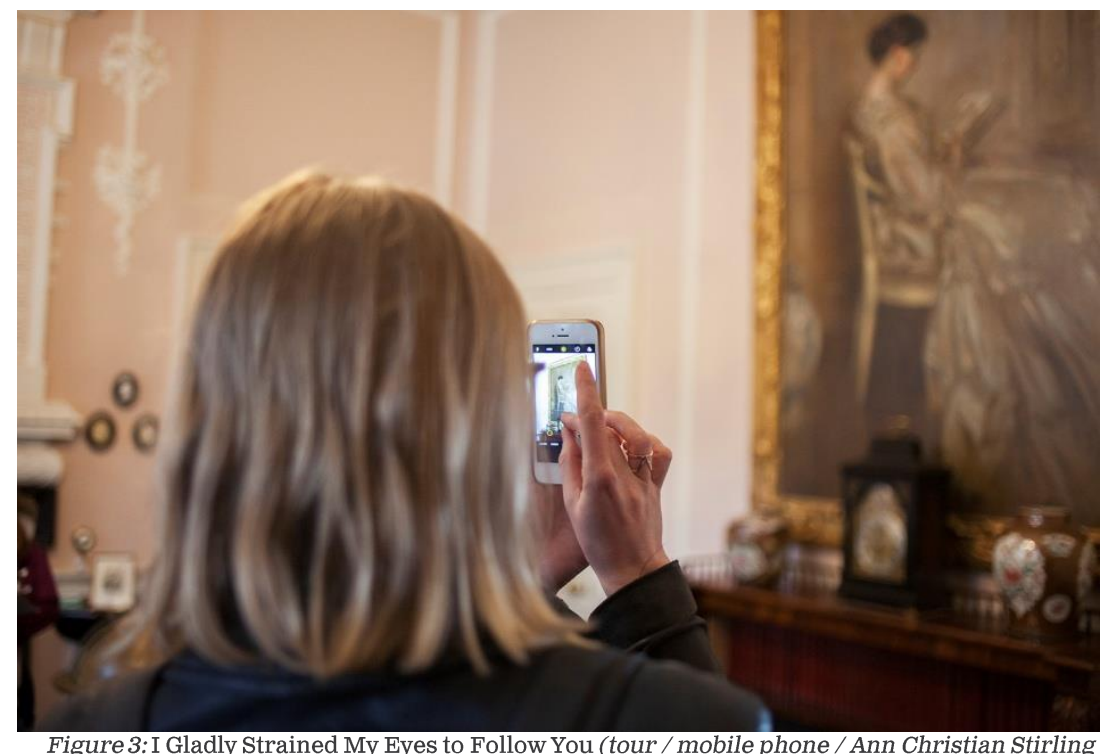

Figure 3: I Gladly Strained My Eyes to Follow You (tour / mobile phone / Ann Christian Stirling Maxwell). Photo: Tine Bek.

SM: Sara Ahmed's Living a feminist life, which I read at the same time as undertaking the residency in Pollok House, 
was an influential backdrop against which to develop a method and approach for I Gladly Strained My Eyes to Follow You.

'Think of this: how we learn about worlds when they do not accommodate us. Think of the kinds of experiences you have when you are not expected to be here. These experiences are a resource to generate knowledge' (Ahmed, 2017, p.10). Thinking about how to make feminist theory work in the places we live and work was central to the development of the artwork, acknowledging the absence of writing on women represented in the house at the same time as using it as an opportunity to explore the politics of location and the potential for overlapping the diverse histories and geographies connected to each of them. A house such as Pollok House offers an opportunity to think about the concentric circles of identity formed by 'memory, the body, the family; by community, tribe or ethnic group; by locale, nationality, language and literature-and the wild tides of invasion, colonization, emigration, exile, nomadism and tourism' (Solnit, 1997, p.9). It's all here, if you look hard enough. Bringing the lives of these individual women together into one text / artwork / performance offered a way of exploring the themes Solnit talks about, at the same time as testing what they might mean contemporarily, within a current Scottish socio-geopolitical context.

\section{The landing}

Unknown lady

Dates unknown

Kate Davis, artist

Untitled

Unasked 
Unspoken

Unkempt

Unaccustomed

Unseen

Unsteady

Unnecessary

Unwilling

Unemployed

Unwise

Undressed

Ungovernable

Unsound

Unhealthy

Unflappable

Unlucky

Unmarked

Unpretentious

Unsightly

Unprincipled

Unable

Unnatural

Unwritten

Unbending

Unreasonable 
Scottish Journal of Performance

Volume 5, Issue 2

\section{Unsettled}

Unstable

Unaware

Uncommunicative

Unwholesome

Unsaid

Untapped

Unbecoming

Unarmed

Untold

Unattached

Unwell

Unstuck

Unashamed

Unknown

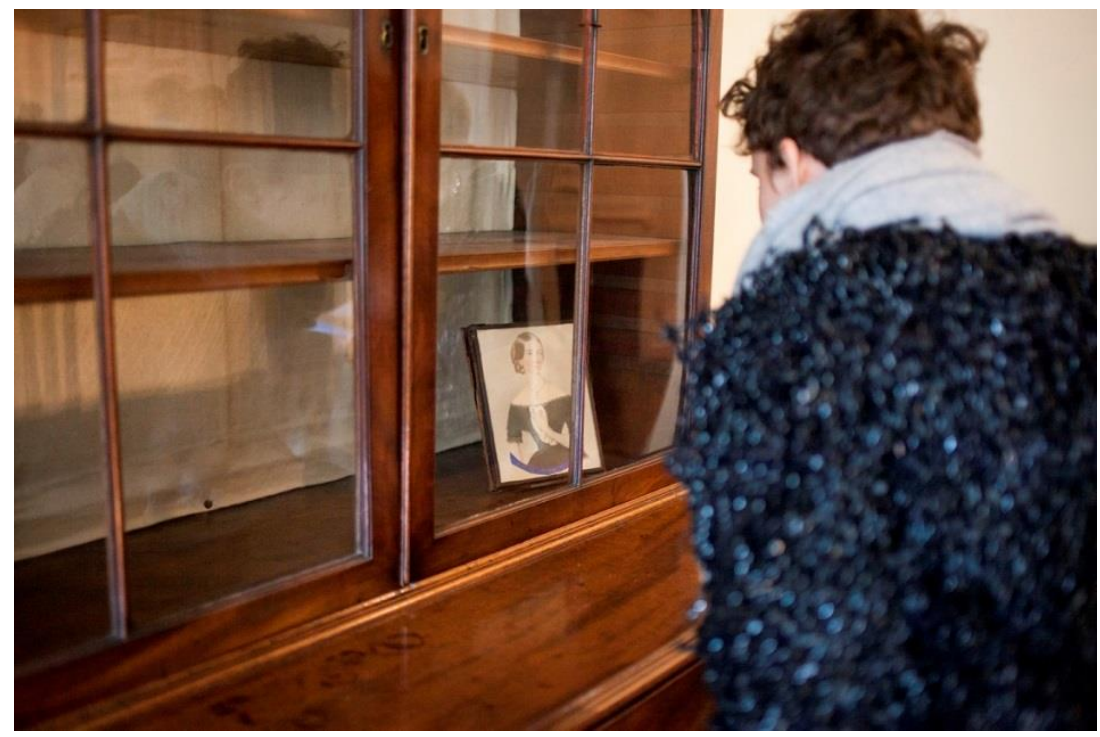

Figure 4: I Gladly Strained My Eyes to Follow You (tour / unknown portrait / the landing). Photo: Tine Bek 
SM: If we understand space as the product of social relations and interrelations then it must "be predicated upon the existence of plurality, in which distinct trajectories coexist' (Massey, 2005, p.9); therefore, any meaningful attempt to represent or narrate a place or space needs to bring together multiple perspectives. A central component of this project was the collaboration with individuals from different backgrounds and disciplines. Eighteen women from the fields of art, literature, academia, education, history and heritage were invited to write a short paragraph of between 200 and 250 words, in response to one of the selected portraits. I asked women whose work, writing, thoughts and lives I knew to connect with the subject of the research. Women who I believed would have something interesting to say and write, who when brought together as a collective would 'use their particulars to challenge the universal' (Ahmed, 2017, p.10), and who ultimately would make an inspiring and challenging community of thinkers. These collaborators knew the subject of the work / research in different ways and wrote about it accordingly. 'Positionality provides a way of understanding knowledge and essence as contingent and strategic-where I am makes a difference to what I can know and who I can be' (Rendell, 2002, p.46). Reading through notes I scribbled down in a sketchbook during a talk entitled Expertise and Experience by professor and educator Anne Boddington at Glasgow School of Art on 12 October 2017, I am reminded of the emphasis and importance she places on communities of practice. 'We care to share' and 'dare to think together' are highlighted in fluorescent orange with an asterisk beside each, in the hope that I'll return and give them more thought. I did, and I Gladly Strained My Eyes to Follow You grew from greater consideration of these two prompts.

\section{Morning room}

Infanta Dona Maria Anna

$1606-1646$ 
Kirsty Leonard, artist

Maria,

What is the history of our correspondence?

What surfaces, what interfaces between us? What punctuations, dispersals, flowings over and through, unformings and reformings has your face performed in order to become the pixels that spread its lighted likeness onto mine?

Your eyes,

the painter's eyes,

the palette,

the canvas,

the wall,

all of the walls,

the probable shrouded cycles of storage,

the stretches and pulls of oil paint that make cracks,

the photographer's eyes,

the camera's eye,

the computer,

the email,

the screen.

The anti-glare coating on my laptop is eroded in the spot over your eyes; your gaze reaches mine minus one filmy remove. 
But in spite of-or because of-this assembly of lenses, I cannot make sense of your face.

We do not correspond.

We say that we can read an expression. Perhaps it is a cliché, but I cannot read yours. Or maybe I read too well. When I try, I identify such a proliferation of expressions so as to efface their meanings. Can you feel amusement, sadness, indifference, boredom, anger, scepticism, relief, impatience, pity, tiredness, sympathy, serenity and contempt all at once? Probably. But I still don't know you.

How different is my attempt at decoding the expressions on your face to the labelling of the imagined feelings of an object? Is the impulse to make it signify similar to the heavyhanded gesture that further encumbers the forgotten skeleton of a building with disgruntledness; or a table top, already maligned by work and leaning elbows, with fatigue?

Your face supports nothing, not even its own expressions. For this, I admire you.

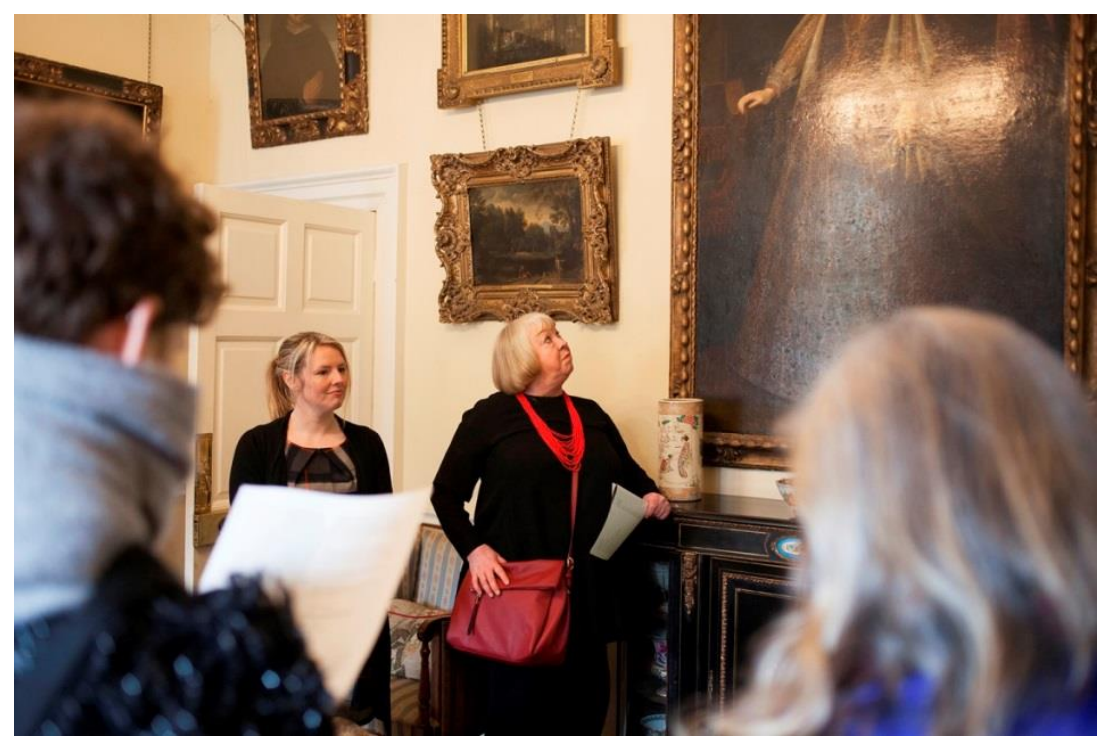

Figure 5: I Gladly Strained My Eyes to Follow You (tour / Sam Ainsley / Infanta Dona Maria Anna). Photo: Tine Bek. 
The FACE, but not the countenance, is a landscape, several landscapes. An entire land parched with drought, the flesh defied. And in the wrinkles, in the creases where the pupils flash with anger, a cheerful incredulity. The network of cracks and furrows represents so many weak points; misery has entered them, infiltrated them and has been welcomed. Waiting for rain. (Lyotard, 1988, pp.184-185).

SM: I return to read this paragraph Lyotard wrote about a photograph of Samuel Beckett aged 80, in his book The inhuman, reflections on time, over and over again. Not only because of the exquisite image Lyotard creates of Beckett in my mind's eye, or how much he reveals about the life and history of his subject in such few words, but more importantly because of the attention and care I know he has paid to looking at and thinking about Beckett's face. The text is tender, detailed, analytical, poetic and expansive, and I wondered how it would be to create a multifarious portrait of the women of Pollok House through this action of close looking.

\section{The family room}

Lady Anne Maxwell Macdonald

1906-2011

Adele Patrick, founder and manager of Glasgow Women's Library

I was around the age you are when I made a startling discovery. In all my looking over the decades at the pantheon of landed women caught by art history (where wealth is frequently marked by the depiction of attentive servants or enslaved people) I had never identified with 'The Duchess', always her subjects. 
How might it feel to be entitled, to stare out into the room, into the world with consummate self-possession? Approximating manhood?

You are not waited on here or adorned with jewels or the forms of 'feminine excess' that on the poor are still so pathologically loathed, so how can I read off your own strident inheritance of patrilineal conviction? I can hear your voice, read the letter you are penning. Is it the skin, the hooded eyes, the hairline, the teeth, that semaphore gun rooms, servants quarters, bell pulls, a retinue of 50 to service a family? Your interpolating gaze evokes paradoxical feelings.

Yours after all is a woman's name nestled amongst the Sirs, Field Marshalls, Viscounts, Major Generals and Earls, one of the six women amongst the regiment of 140 men given the Freedom of the City. A rare, garlanded woman acknowledged by the City Fathers and now by women searching for heroines hidden from history.

You evince an elusive unorthodoxy, caught in the act of decisive and yet casual largesse, giving a gift; to imagine this house, vista, walled garden as our own. Your mouth enunciates: To give land means to have owned land. 


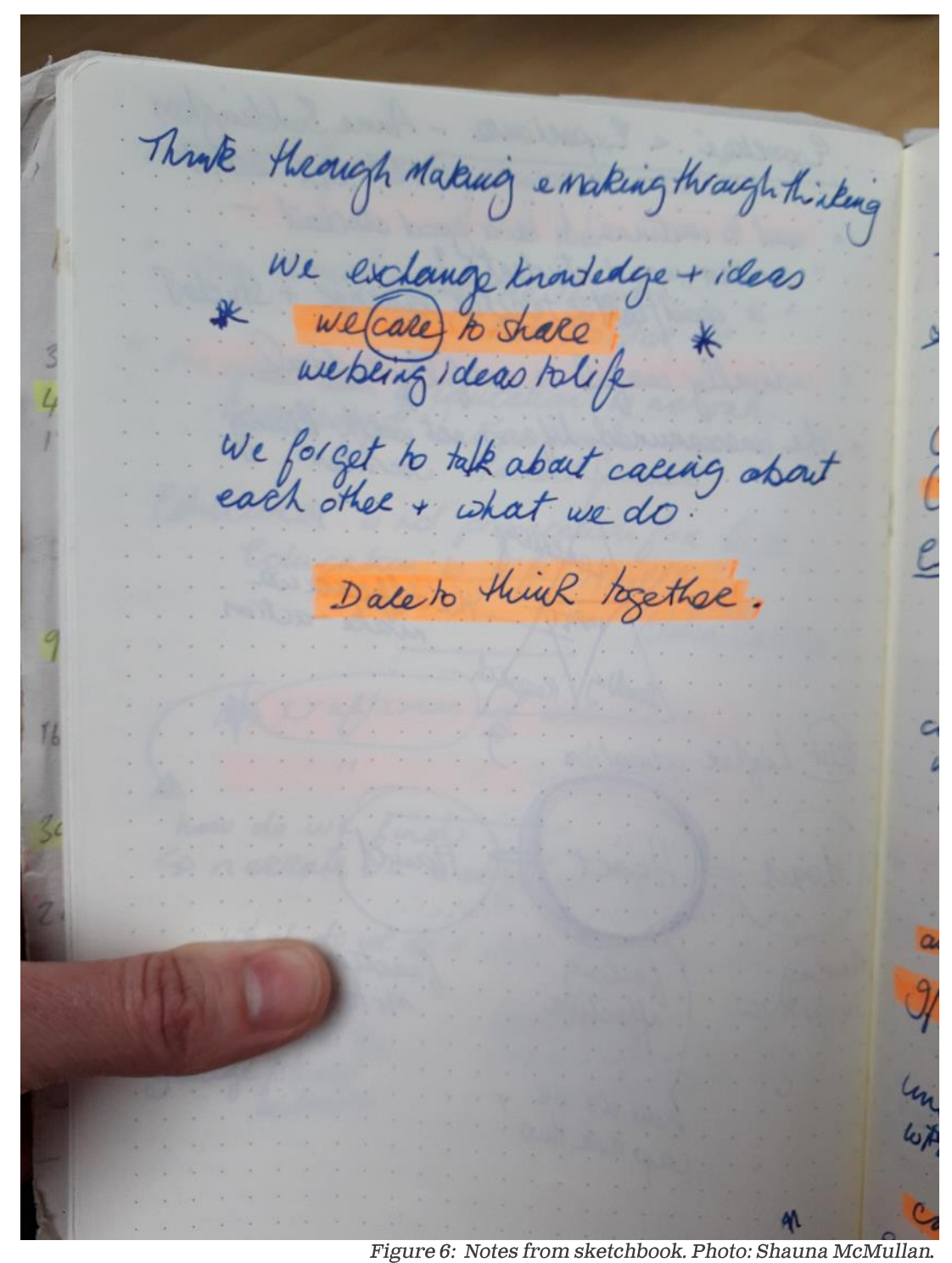

SM: I asked each writer to focus on the face. The content could be factual, fictional, imagined or real and could be written in the first, second or third person. It might speak directly to the woman in the portrait; to the viewer of the portrait; to the author; or be the words of the woman portrayed. It might include more than one voice. The important thing was to pause, to pay attention, to look closely, with care and in detail; to read the face. The result is a compilation: a female coloured, composite text, that reveals a portrait of Pollok House which is complex, detailed, nuanced, subtle, poetic, practical, abstract, intimate, descriptive, funny, theoretical and political. The 
text is a place we wrote ourselves (and each other) into, which we occupy, and where we are present.

\section{The silver corridor}

Manon Jeanne Roland

$1754-1793$

Siân Reynolds, historian \& translator

Framed like a cameo, this portrait shows a young woman in eighteenth century dress, with a frilled cap over her curly brown hair. She has perfect, unmarked skin, large eyes, and a serious, rather steadfast expression.

All the signs are that this was painted well after the death of the subject, in the post-Revolutionary years when there was a cult of Madame Roland as a victim of the Terror, who said as she went to the guillotine: 'O Liberty, what crimes are committed in thy name ${ }^{2}$. The words are entirely in character for this enthusiastic revolutionary, the political wife of a minister, who shared the fate of the Girondins.

The portrait, though, is idealised, and based on no image from her lifetime. As a teenager, Marie-Jeanne (aka Manon) Phlipon described herself as having 'a rather large mouth', a 'voluptuous chin', and a high-coloured complexion. 'My eyes are not big, grey-brown, but they have an open, frank gaze and are crowned with eyebrows as dark as my hair.... My nose used to trouble me, I thought it was too big at the end'. She usually wore her brown hair in a jockey-cut with a plait. The most true-to-life surviving image of her is a miniature in the Archives Nationales in Paris, showing her with loose, very dark hair, and wearing a muslin gown. Owned by a man who loved her, it isn't flattering-she does 
Scottish Journal of Performance

Volume 5, Issue 2

indeed have a wide mouth and a large nose-but it is attractive and romantic.

Our picture is perhaps an early example of the airbrushed celebrity portrait.

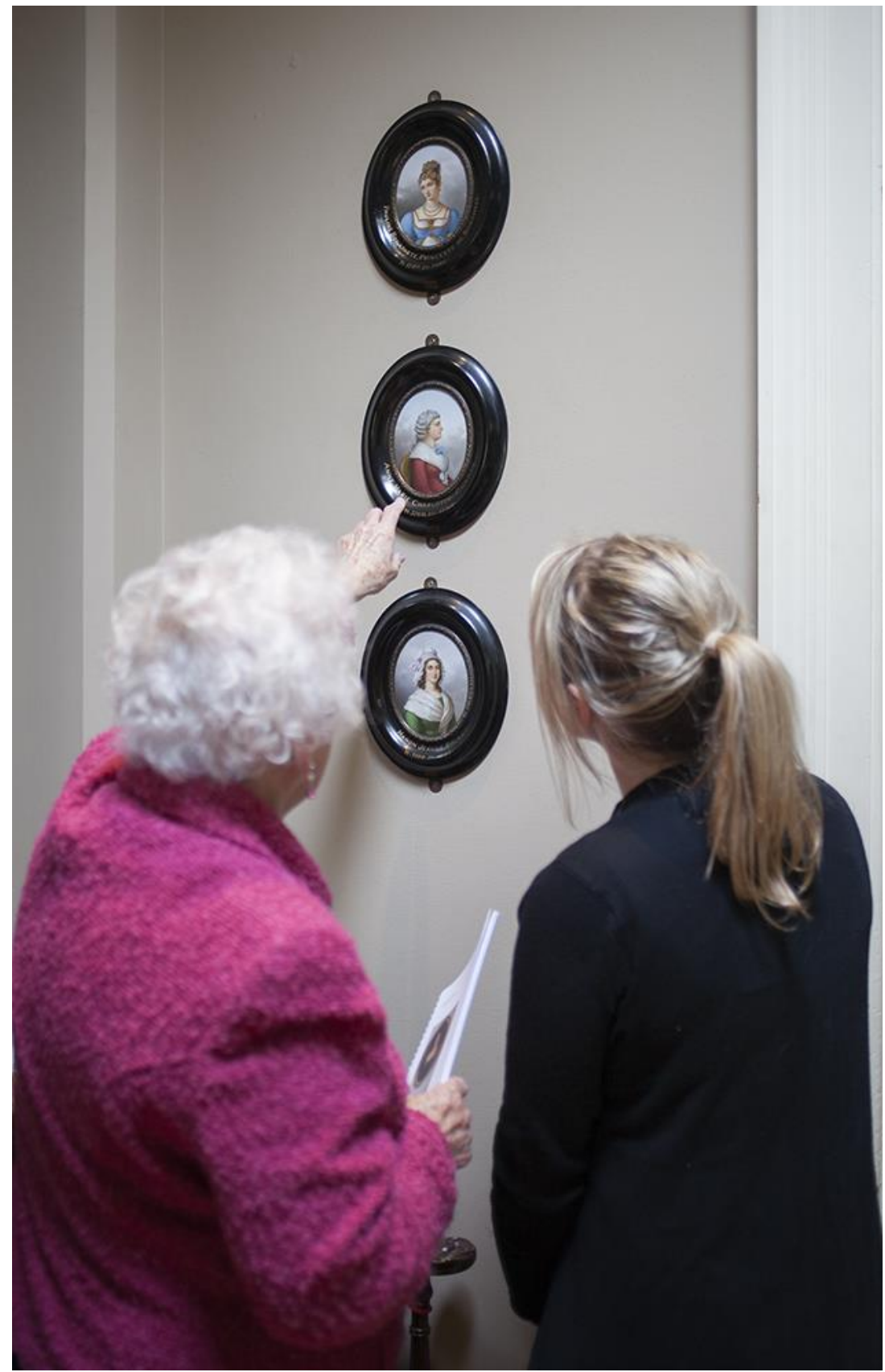

Figure 7: I Gladly Strained My Eyes to Follow You (tour / Wilma Morrison / Karen Cornfield / Manon Jeanne Roland). Photo: Tine Bek. 
SM: Within the daily and weekly routines of Pollok House, guided tours are common practice. They are part of the everyday and are led by a team of dedicated, experienced, knowledgeable and enthusiastic volunteers, looking at the House's collection of art and artefacts and sharing its history. Very early on during my residency I realised that the holders of many of the facts, anecdotes, histories, details and stories associated with the House were the volunteers, some of them having worked within Pollok House for over 40 years. They knew the House inside out and when they didn't know something, or were uncertain, they knew someone who would. They were its custodians and I watched and listened to their tours with interest and curiosity. Each tour was different depending on who led it, even when the material and subject was the same. Each guide would place an emphasis on something distinct; each would edit and adapt the material to suit their predilections and each would introduce their own anecdotes and interpolations by-the-by. Two things they all had in common were their unbound enthusiasm for the House, and their embodiment of the narrations they shared with visitors. They owned the stories they told, and I believed them. I had been thinking about something Nikos Papastergiadis talked about when he was thinking through Lefebvre's theory of the everyday and how the concept of everyday life can 'illuminate complex ways in which subjects exercise their potential to be emancipatory and critical' (Papastergiadis, 2006, p.32). I wanted to consider developing an artwork for Pollok House from the perspective of its everyday.

Sixteen volunteers signed up to lead I Gladly Strained My Eyes to Follow You, and we worked closely in the weeks leading up to the exhibition getting to know the texts, opening up their potential meanings and readings, and hearing ourselves speak them out loud in front of the portraits in the various rooms and corridors throughout the House. The contributors had done their work in writing the texts for the tour, now the volunteers took the time 
necessary to own them. Some of the words and sentences in the texts were difficult to read and speak; some of the texts were provocative and challenging; some obscure, elusive, and abstract. Yi-Fu Tuan says in his book Space and place, that to experience in the active sense 'requires that one venture forth into the unfamiliar and experiment with the elusive and uncertain' (Tuan, 1977, p.9), and that's what each volunteer did. Tuan describes experience as overcoming of perils. The word 'experience' shares a common root (per) with 'experiment', 'expert', and 'perilous'. The 16 volunteers who performed I Gladly Strained My Eyes to Follow You stepped out of their comfort zones, experimented with their normal everyday routines and became experts of this new subject. In doing so, they invited visitors and audiences to Pollok House (and Cabinet Interventions / Glasgow International) to share this experience that would hopefully make us think about the absence of women's achievements from official histories, and the importance and responsibility we all have in acknowledging and challenging these gaps. Jacques Rancière writes about how artists and researchers build a stage where we frame stories of new adventures in new idioms that cannot always be anticipated, and how important the spectators' role is in interpreting and translating these stories. I Gladly Strained My Eyes to Follow You involved various communities of performers, spectators, translators and interpreters; the writers, the tour guides and the visitors to the House, each responsible in a slightly different way for interpreting the material. 'It calls for spectators who are active as interpreters, who try to invent their own translation in order to appropriate the story for themselves and make their own story out of it. An emancipated community is in fact a community of storytellers and translators' (Rancière, 2007. p.281).

Is it possible that a guided tour of a National Trust for Scotland property might contribute to a more emancipated community? I think it is. 


\section{The print room}

Lady Anna Maria Stirling Maxwell

$1826-1874$

Shauna McMullan, artist

Your dress caught in the fire-it was the 21st November 1874, one hundred and forty-four years ago.

How are you surrounded, by whom and by what? Circles and lines, some seen, some not.

It begins with the line of gold that circles your face-a line that traces your eyebrows, upper and lower eyelashes, runs down through your centre parting along the right-hand side of your nose and outlines the sharp edge of your hairline. It is extended slightly with the gold chain sat heavy on your chest and all of this is drawn out by the sheen from your golden hair.

You fell forward and burnt your hand badly.

The gold turns to black in the form of a frame whose tone, weight, scale and craftsmanship vie for our attention, competing with your image.

Your hand had to be amputated.

Situated and fixed as you are here, next to the door, in the print room, between the library and music room, the circles ripple out-connecting you, and this house, with women who have lived and moved across the length and breadth of Europe. I doubt you ever imagined the company you would 
come to keep. Jeanne from Paris, Anne Marie from Lignières, Isabella from Fontainebleau, and Dona Maria and Marie Theresa both from Madrid. Elizabeth from Glasgow, Anne from Edinburgh, and Anna Maria from Monimail in Fife. Sally from Shrewsbury, Arabella from Hackney and Caroline from London. Rufina came from Seville and Anne from Cigales, not forgetting Isabella Clara Eugenia from Segovia.

You died 17 days later on the 8th December.

We see neither of your hands here. Both are hidden from our view, as is the small gold circle on your left-hand ring finger, pressing lightly on your vena amoris, ending in a line running directly to your beating heart.

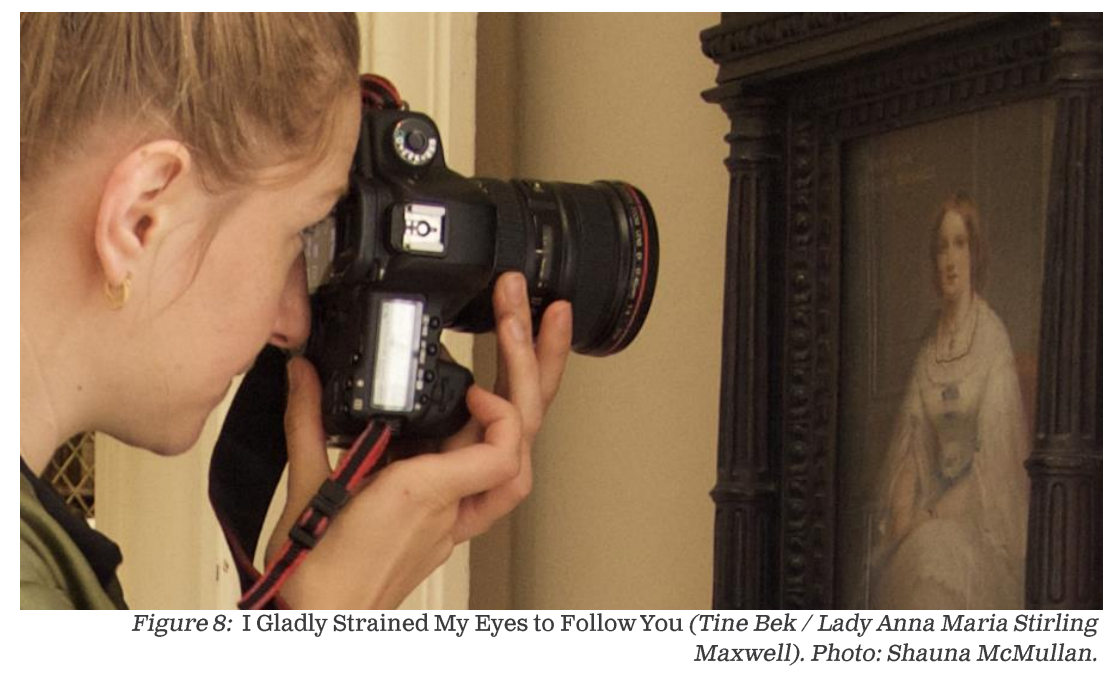

\section{Acknowledgements}

I Gladly Strained My Eyes to Follow You, texts by: Sam Ainsley, Elaine Ang, Christine Borland, Jenny Brownrigg, Karen Cornfield, Kate Davis, Fiona Dean, Laura Edbrook, Moyna Flannigan, Laura González, Victoria Horne, Kirsty Leonard, Jennie MacLeod, Shauna McMullan, Adele Patrick, 
Siân Reynolds, Stephanie Smith, Sarah Tripp, and Clara Ursitti.

I Gladly Strained My Eyes to Follow You, tour guides: Jan Allen, Jane Black, Jim Boulton, Katrina Cobain, Linda Dempster, Ruth Eason, Hester Harvey, Robert Macaulay, Jennie Macleod, Barbara Mann, Bill Mcnamara, Megan Rudden, Morag Milner White, Wilma Morrison, Joan Pethrick, and Nan Steele.

Supported by: The Royal Society of Edinburgh, Glasgow School of Art, Glasgow International, and The National Trust for Scotland.

\section{Notes}

1. 〈https://cabinetinterventions.org/>. ${ }^{[\uparrow]}$

2. There are several contemporary sources for this and it is usually quoted in English in the form given (not my translation, it is a standard one). It was passed on by eye-witnesses and is widely repeated by contemporaries and historians but the earliest I could find was by Riouffe (1795, p.70), who was imprisoned with her. I refer to it on p. 286 of my book (Reynolds, 2012). ${ }^{[\uparrow]}$

3. Her self-description comes from de Roux (1966, p.258). You have it here in my translation, which is on p.53 of my book (Reynolds, 2012). ${ }^{\lceil]}$

\section{References}

Ahmed, S., 2017. Living a feminist life. Durham: Duke University Press.

De Roux, P. ed., 1966. Mémoires: de Madame Roland. Paris: Mercure de France.

Horne, V., 2016. The weight of history. In Footnoting the Archive: Endnotes. [online] Available at: 〈https://mapmagazine.co.uk/weighthistory> [Accessed 24 August 2018].

Lyotard, J.-F., 1991. The inhuman: reflections on time. Translated by G. Bennington and R. Bowlby. Cambridge: Polity Press.

Massey, D., 2005. For space. London: SAGE Publications. 
National Trust for Scotland, 2018. History of the trust. [online] Available at: 〈https://www.nts.org.uk/our-work/history-of-the-trust〉 [Accessed 20 August 2018].

Papastergiadis, N., 2006. Spatial aesthetics: art, place and the everyday. London: Rivers Oram Press.

Pollok House Residencies and Exhibition. Cabinet interventions. [online] Available at: 〈https://cabinetinterventions.org/〉 [Accessed 21 September 2018].

Rancière, J., 2007. The emancipated spectator. Artforum International. Vol.45(7), pp.271-280.

Rendell, J., 2002. Travelling the distance / encountering the other. In D. Blamey, ed. 2002. Here, there, elsewhere: dialogues on location and mobility. London: Open Editions. pp.43-54.

Reynolds, S., 2012. Marriage and revolution: Monsieur and Madame Roland. Oxford: Oxford University Press.

Riouffe, H.R., 1795. Mémoires d'un détenu pour servir l'histoire de la tyrannie de Robespierre Paris: Mathé \& Louvet.

Solnit, R., 1997. A book of migrations: some passages in Ireland. London: Verso.

Tuan, Y.F., 1977. Space and place, the perspective of experience. Minneapolis: University of Minnesota Press.

\section{About the author}

SHAUNA MCMULLAN is an artist and lecturer. Her main areas of research are feminism, geography, and collective practice. Previous projects include: Cabinet Interventions, Pollok House, Glasgow (2018); The Albert Drive Colour Chart, Tramway, Glasgow (2013); The Blue Spine Collection, Glasgow Women's Library (2010); Travelling the Distance, commissioned by the Scottish Parliament, Edinburgh (2006); and Via, shown in the Toyota Museum of Modern Art, Japan (2005). She works as a lecturer in the Department of Sculpture and Environmental Art at Glasgow School of Art where she is a contributor to the Reading Landscape Research Group; she is also part of the international research network Creative Centre for Fluid Territories (CCFT). 
INTERVIEW:

\title{
Trio HLK
}

\author{
BENJAMIN REDMAN
}

DOI: 10.14439/sjop.2018.0502.05

Publication date: 30 September 2018

Trio HLK is an ensemble that draws on elements of jazz and contemporary classical music, and pushes the boundaries of both genres. They recently collaborated with Dame Evelyn Glennie (arguably the world's foremost solo classical percussionist) and Dr Steve Lehman (contemporary jazz saxophonist and Guggenheim Fellow) on their debut album recording, Standard time. The trio launched Standard time at a concert featuring Evelyn Glennie at the Queen's Hall, Edinburgh, on 13 May 2018. This article is based on extracts from an interview conducted several days after the concert with Richard Harrold and Richard Kass, in which they discussed a wide range of topics, including their rehearsal and compositional processes, collaborations, performing, and development as an ensemble.

\section{Introduction}

Formed in Edinburgh in 2015, Trio HLK consists of pianist and composer Richard Harrold, drummer / percussionist Richard Kass, and eight-string guitarist Ant Law. The ensemble was described by BBC Jazz on 3 as 'One of the most exciting young ensembles to have emerged in the last year' (Ubuntu Music, 2018). Many of the compositions on their debut recording Standard time are based on 'standard' jazz tunes, which are deconstructed and then reconstructed using elements 'such as fragments of melody or harmony, which then become the raw material for intricate new 
pieces, resulting in familiar threads leading the listener into distant territory' (Trio HLK, 2018).

Evelyn Glennie commented, 'Collaborating with Trio HLK has been a wonderful journey of exploration, a challenge that I have thoroughly enjoyed. It has allowed me to venture out of my comfort zone, explore new rhythms and marvel at the Trio's compositional prowess' (Ubuntu Music, 2018).

The band are performing an ongoing series of concerts throughout 2018 and 2019, details of which can be found here: http://www.triohlk.com/itinerary.php

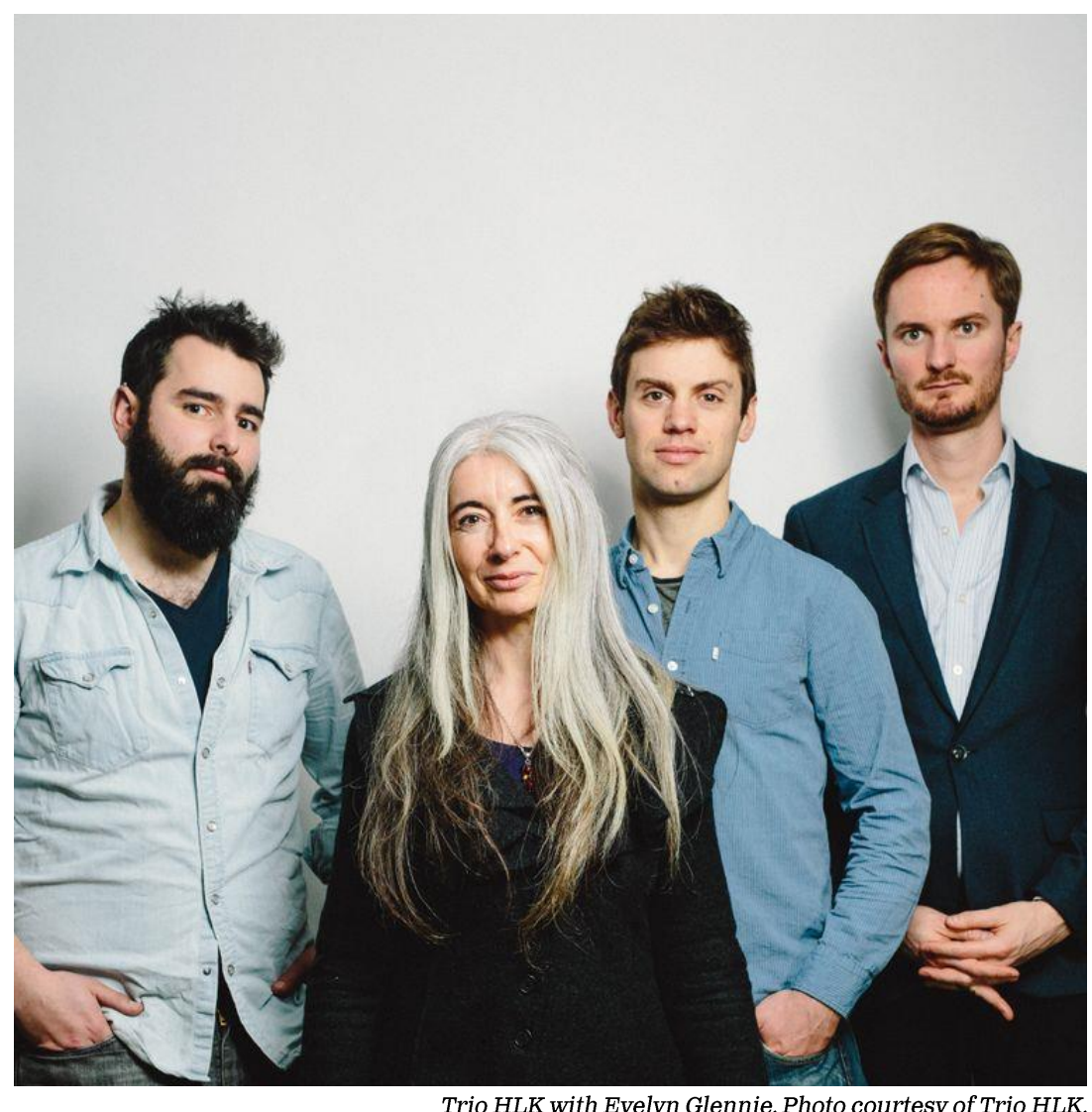

Trio HLK with Evelyn Glennie. Photo courtesy of Trio HLK. 


\section{Compositional process}

Benjamin Redman: Could you talk me through some of your compositional processes? I know from the Standard time sleeve notes and from what you talked about at the concert, a lot of the tunes are based on deconstructed standards.

Richard Harrold: I often choose a standard that has really strong melodic or motivic content, things that have a really strong identity, and then just take those bits and then work with them as much as possible. So, it's just borrowing chunks of material that hopefully people recognise, or at least think they might know-they're supposed to be quite on the edge of recognition.

\section{Smalls}

RH: The first tune on the album is 'Smalls'. The structure consists of two main rhythmic forms. The first one you hear as an extended introduction-that section uses the descending whole tone motif from the start of 'Blue in Green' [Miles Davis tune from the album Kind of blue].

Richard Kass: It's a four-bar form and the time signatures are 13/16, 11/16, 13/16, 9/16.

RH: And that's it, it's just a four-bar pattern, but that's cycled as a background rhythmic pattern and we improvise freely around that. Usually, one of us is asserting that form at any one time. And then the second rhythmic structure is a bit more complicated; it's just an eight-bar form, but it's switching between thirteens, elevens, nines-basically, irregular time signatures. It's not terribly brutal to learn, but again, it's long enough and unpredictable enough that probably nobody in the audience quite has it learned by the end of the piece! 
RK: It also flies by-it is crotchet equals 120 [beats per minute], but those notes are all dotted, so when improvising on the form, if you forget where you are, a couple of bars can go by before you manage to make eye contact to see what's going on.

$\mathrm{RH}$ : One of the main things that we like to do in all of the tunes is play around with your perception of where the beat is, so when it moves by quite quickly it can sound like it's in four, but a wonky four. So that thirteen sounds like a $4 / 4$ groove that's a bit out of time, but we're all 'out of time' in unison. It's a fun effect-strict counting that gives the impression of sloppiness.

https://www.youtube.com/watch?v=dQMsp2By9z4

Video: Trio HLK featuring Evelyn Glennie 'Extra Sensory Perception part i'.

Extra Sensory Perception parts i and ii

RH: The next tracks are 'Extra Sensory Perception parts i and ii'. We did discuss keeping them as one track, but then we thought it was quite a nice compositional thing to have it chopped into these two quite different sections; so part $i$ is the vibes and piano intro, and part ii is the band piece, but it's based on the same material.

BR: So, it's based on the Wayne Shorter tune 'ESP'; which elements did you extract from that?

$\mathrm{RH}$ : For the vibes and piano intro, the ostinato that you hear is the original tune with the melodic pattern condensed, with all the rhythm taken out of it. It just becomes an ostinato and it kind of sounds like a swing rhythm, but again, slightly out of time. It's a bar of $9 / 8$, but hopefully it 
sounds like a wonky three-three-two, and then on top of that you get lots of overlaid melodic fragments.

RK: That was one of the first tunes that we played when we started playing together. In some ways, I still find that the hardest because I think I'd have to go back to it to play it in the same depth that I play some of the other tunes. I'm going to revisit it, I'm just waiting on my crotales arriving, and there's going to be a couple of sections where I'm going to play some pitched stuff on it in unison. But it's funny how that happens-the older material is more frustrating to play through, because at the time I maybe didn't have the same facility or the ideas, it was like just trying to get through the tune! But once you get used to the rhythmic material, all these things you've worked on, you start to see how they can work. I look at it now and I can see all the possibilities.

\section{http://www.triohlk.com/downloads.php}

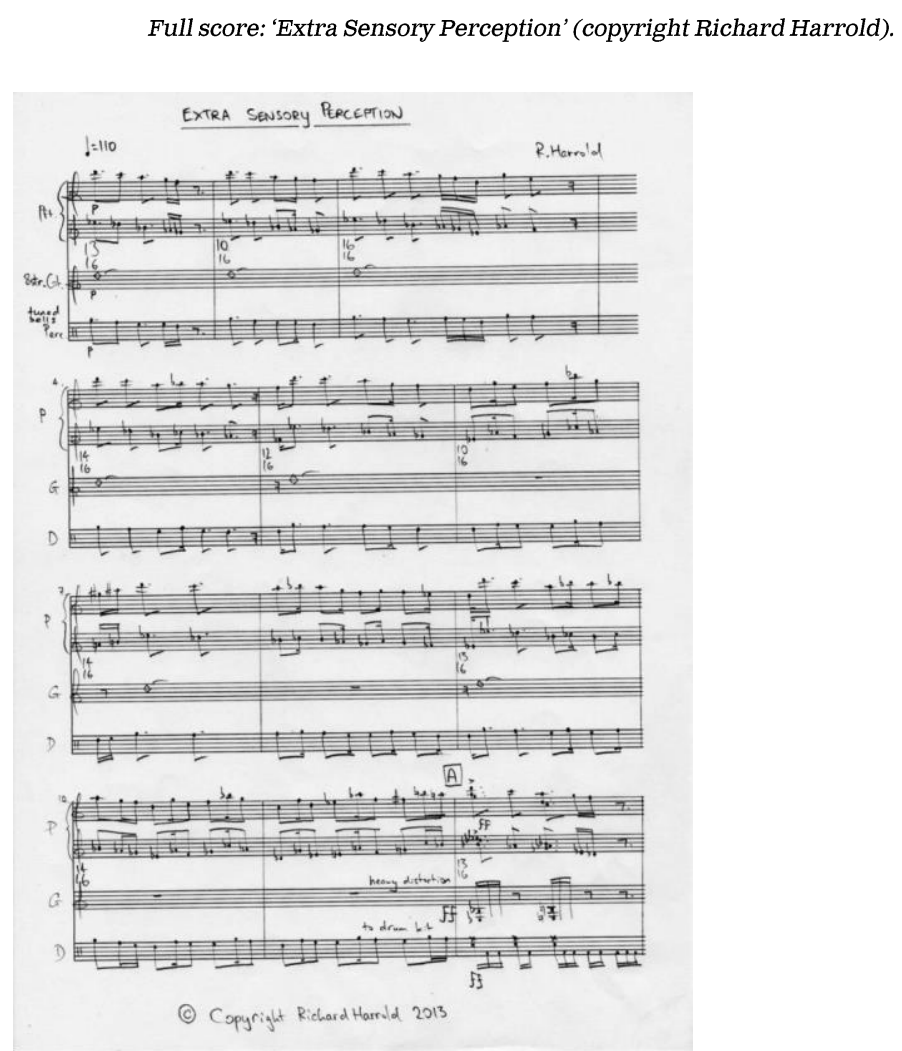

First page: 'Extra Sensory Perception' (copyright Richard Harrold). 
pains parts $\mathrm{i}$ and ii

RK: 'painS' is based on the Chick Corea composition 'Spain', which has got quite a lot of ideas in it; this one is maybe the most full of material. So really, the whole composition is about six sections long, and each one of them works on a different part of the original tune.Hopefullythey're fairly recognisable, they're a bit less obscure than the material used in some of the other pieces.

$\mathrm{RH}$ : Part $\mathrm{i}$ of this composition is an improvisation by Steve Lehman; I sent him a two-bar motif, and this movement is just an improvisation on that motif.

Twilt

$\mathrm{RH}$ : The next track is 'Twilt', based on 'The way you look tonight', but it's 'The way I look tonight'. A lot of the titles are just in-jokes. 'Twilt' is based on perceived beats, there are quite a lot of expanding and contracting false beats. Something I do for quite a lot of the tunes is rather than thinking of a chord sequence, I will use a particular intervallic idea. This tune is based on perfect fifths and major seconds, different combinations of them being placed next to each other in different configurations. I'm just moving these symmetrical shapes around each other, and the harmony emerges from that. Quite a lot of the tunes have that sort of harmonic approach.

\section{Dux}

RK: Rich had originally come up with a piece based on some motifs that would be heard in Latin or Afro-Cuban music and I thought it would be a good way to explore doing some stuff with the clave. I guess quite a few times, an idea comes up in the tune, and if it works, I then try and use the tune as a way to really explore that idea, to go into depth with it. So, as well as playing it within the trio, I've added it to my 
vocabulary. A lot of the drum parts, and a couple of bits of the composition towards the end, get based on the 3:2 rhumba clave, and the very start of the tune is like the rhumba clave in four different sub-divisions, layered so you hear them at four different tempos, but they're all metrically related.

RH: 'Dux' is all in 4/4; actually, it's the only tune on the album that is. But then, the clave is kind of pinning the whole thing together with all these other motifs shifting around each other in different rhythmic patterns.

RK: On some of the tracks on the album, the drums serve to highlight the interplay of the guitar and the piano. In the 'head' of Dux, the piano plays montuno vamp patterns and the guitar plays the tumbao bass pattern, and the drums pick out both parts. While they shift around each other, the clave continues in $4 / 4$, pinning the two together. Several of the tracks on the album use the drum set as a sort of glue for the shifting polyrhythms of the other instruments.

$\mathrm{RH}$ : It helps pin these things together. Without the drums working this way, some of the parts of complicated counterpoint might seem a bit too unrelated to be cohesive, but the kit helps to bind the thing together. However, this orchestrational technique also means that it's very obvious when one of us messes up!

\section{Chewy}

RK: That's the shortest tune on the album, and has one of my favourite solo forms in it, because there are quite a lot of time signature changes. There's a sort of distorted symmetry at the start of the form, and a real asymmetry at the end of the form. At the start of the form, there are always three bars of $4 / 4$, followed by an irregular time signature. 
The first group of these is three bars of $4 / 4$ and then a bar of $3 / 4$; the next group is three bars of $4 / 4$ and a bar of $9 / 16$; the next is three bars of 4 then 11/16; and finally, three bars of 4 and a $7 / 16$. So, with all the $4 / 4$ stuff, it's quite an easy form to play on, but punctuated by these interesting moments of irregularity. It sounds quite mathy, but it's really not. After a while you start to realise lots of opportunities for overlaying different rhythmic patterns; for example, dotted notes can go across whole swathes of sections, which helps to create tension and release, and the numbers happen to work out so that dotted patterns resolve at the starts of sections. For me, the composition has a really interesting solo form-there are a lot of different things that can be explored.

The coda is another example of a section in which the drums pick out the two parts of counterpoint as a kind of orchestrational glue. Behind this, the drums also play a Bossa Nova style bass pattern which keeps getting chopped up. In fact, the whole piece has that sort of samba rhythm driving it, but often with extra bits of beats chopped in or out.

RH: It's a very contrapuntal piece. I really love J.S. Bach's two part inventions, the way that the lines are always perfectly interweaving; separate, but totally interdependent. And the coda to this piece is a sort of counterpoint exercise in that vein, a counterpoint exercise from hell!

\section{Stabvest}

RH: It was originally called 'Stabfest', but there's already a version of 'Stabfest' out there, so we renamed the album version. It was called 'Stabfest' because it's so full of stabs! Rhythmically, it's based on groups of five, seven and three; a lot of it is in 4/4, playing with different groupings over a $4 / 4$ pulse. Because we're not stating the actual pulse, it gives the 
effect of speeding up and slowing down. If you're not hearing the true pulse then you get this shifting effect.

RK: And in both the solo sections there's an interesting thing-both of the solos in the rhythm section can be played in four, or can be played within the groupings. So, with quite a lot of the tunes where that's the case, we can go into different gears or try and play in the sevens for a while, and then the whole rhythm section can be speeding up and slowing down. On the other hand, it can be really open, so you can start it very sparse, and then suddenly it morphs into something else.

$\mathrm{RH}$ : But we're really just counting the same thing underneath it. This is another one that is all based on the same harmonic idea-it's just second inversion chords. Before I figured out their order, I just sat and played through different configurations and second inversions placed next to each other, decided which ones were good, and then just sat and arranged them. They're all just major triads, and the harmony for the solos just emerges from those patterns.

\section{The Jig}

RH: It's from J.S. Bach's 'First Cello Suite in G Major', but you can't really hear it, it's been so distorted. The compositional process was quite non-linear for that piece, it's been through a lot of incarnations. Originally, two of the sections that are still in the piece had the melody superimposed and reharmonised, and it was reworked and revised a lot; and then, essentially, most of the melody has been airlifted out. I quite like the idea of that though, it's almost like it was a sort of scaffolding to build this piece, and then the scaffolding has come down, but the piece is there because of that scaffolding. 


\section{Rehearsing and performing}

BR: How long does it take from writing a chart to having it rehearsed and ready to perform?

RH: They're always evolving, but I suppose it's definitely months, rather than days. Each of the pieces generally has a fairly complicated improvising form as well, so that's often one of the biggest obstacles. Learning the dots is fairly tricky too, but that's just a matter of bedding them in; whereas, being able to freely improvise over a new rhythmic framework, it has to be really deeply ingrained so that you can actually hear phrases and rhythmic patterns against it, so that's the stuff that really takes lots of playing in.

RK: Normally, we can quite easily play through the parameters of the form, but having enough headroom to be playful and musical with it, and be responsive, and to be really thinking and able to concentrate on the tempo for example; you just have to get the stuff to the point where you've got the headroom to play it and not be counting. The goal is to play it as well as you'd just be playing a $4 / 4$ blues.

$\mathrm{RH}$ : It's still a work in progress with most of them to be honest. Some of them are getting quite comfortable now, but we're definitely still improving them.

RK: One of the reasons they can take a long time is that we play through them and things need to change, parts change. Almost all of the charts have got things that are scribbled out.

$\mathrm{RH}$ : It's about making them feel the correct length, and after playing something quite a bit, it might seem fine at first, but then we might feel it's just not sitting right in this bit, and we need to take that out. It's a constant workshopping process, 
which is one of the great things about working in a band where you rehearse so regularly-it's not like one of those gigs where you show up and hand the parts out.

BR: I noticed you were wearing in-ear monitors on stage.

RK: We're playing in a lot of different large spaces on this tour with Evelyn, and in spacious venues, on-stage monitors make a big difference to the overall sound. Not having monitors on stage makes it a lot easier to amplify an acoustic sound and make it sound good: not too loud at the front, and not too quiet at the back. It also means the sound is really consistent for us from gig to gig. I think in the past when we've used wedges [floor monitors], because the music is quite loud at points, the tendency is for the volume to creep up. It creates a stage volume that really affects the sound in the venue. So, my favourite way to play now is when we play almost acoustically, just a guitar amp and nothing else!

RH: We've started doing more and more trio gigs without any amplification, which is quite nice. As long as we've got a decent piano and a smaller drum kit, it works quite well.

RK: And it's been great learning to play with the same intensity, but quietly. It's involved, for me anyway, some technique changes, but it's been amazing for being able to play across the dynamic range and separate all those things out. When I'm practising, I might think 'OK, I can play that, but will I be able to play it in the Leggate Theatre, when Rich $\mathrm{H}$ is on an un-amplified grand piano and the room has got a three-second decay?' It just changes your attitude to practising everything you do. Now that we're frequently dealing with so many different spaces and levels of amplification, you have a reason to practise whatever it is 
you're practising at all dynamic ranges, and to try and master the same articulation.

BR: How much do you rely on visual cues on stage?

RK: Because of the nature of the forms being quite complicated, things are normally cued a lot. So, if you miss a cue it can be difficult, like if somebody goes on and somebody else doesn't, then it can cause a bit of mayhem. So, on stage we always have to have a really good line of sight. We make decisions about putting things in places where sometimes it's not great for the audience. We try and avoid that, but you know, sometimes Rich $\mathrm{H}$ might have his back to the audience, which probably isn't ideal. But if he was further over and at a better angle, then I wouldn't be able to see him, which might cause problems!

RH: Yes, I definitely look over at Kass a lot, probably more than I even realise; and actually, there are probably visual cues that I'm responding to that I'm not even really fully aware of. Line of sight is crucial for playing this music.

\section{Instrumentation and genre}

BR: I noticed you have some custom bells and cymbals on the kit, and you mentioned about getting crotales, are you going to be using more tuned percussion?

RK: That's the plan, yes. I guess at this point, I'm really lucky to have an endorsement with Sabian [cymbal manufacturer]; they basically opened the door to me being able to experiment with quite a lot of different things, so the idea is to integrate the crotales. I'm really interested in four-way coordination [using all four limbs], which I think is still very early on in its development. I think what could be done with the kit could be so far beyond where it is now. I really like 
the idea of maybe using the feet to be playing kicks and snares, and trying to do some harmonic stuff with one or two hands. Certainly, there are sections of music where I could just play some tuned percussion, but I like the idea of maybe having a bit of both in there somehow. That's certainly something I'd like to investigate more, but I could lose a couple of years to that, you can go quite deep into that kind of thing!

RH: This music sounds a lot like jazz, but, I think that's mainly due to the instrumentation. I really like the idea of the drum kit expanding into something more like percussion, because for me, this music is at least as connected to twentieth-century classical music as it is to jazz.

BR: What was the motivation for Ant getting his eight-string guitar?

RH: He's learned the eight-string just for this project! Since we don't have a bass player, it's great having two instruments that can still inhabit that register. So, we can share that role, or chose to leave space down there.

BR: We've already touched on genres, would you prefer not to be pigeon-holed?

RH: I think it's very hard to talk about musical genre at all these days. All these different genres are constantly feeding into each other and influencing each other. I think there are a lot people from the non-jazz world who might be interested in this music, and particularly those people who are interested in contemporary classical music. We're keen to reach as wide an audience as possible. 
RK: It's a difficult one to contemplate as it's all so interrelated. Everything is so cross-pollinated now. One of the things that the three of us in the trio share is an interest in great composers, great performers, improvisation, rhythm, and harmony. And there is so much amazing, intelligent music happening in so many different areas right now. One example would be electronic music. There is a whole generation of players, especially drummers, who are reverse engineering electronic music techniques and taking their influence from that. Jojo Mayer has developed drumming techniques that no one else has really used before, in order to replicate that music live. So, electronic drum programming and sampled music are influencing the performer, and even the performance and the technique to some extent. I find it hard to separate any of it, it's all just music, and interesting musicians trying to produce good music.

BR: Can you tell me a bit more about what interests you about JoJo Mayer, is it more his techniques or his musical concepts?

RK: Well both-he's broken both the techniques and the concepts down in different areas through his DVDs and through his TED talks. I was fortunate to do a little bit of studying with him a few years ago where I learned a lot about technique, which I'm still trying to work on, but he's obviously developed ways of playing the cymbal and the snare drum very quickly with fast bursts of motion. People saw Buddy Rich do some of that stuff, but he's really worked that vocabulary, with arguably a greater dynamic range, into a lot of music which requires that technique to be able to play such fast cymbal work that was originally played much slower, and then sped up in samplers. And even the design of the instrument-he's designed these dry cymbals which sound very sampled. And then there's his theory of reverse engineering, where he's taking the vocabulary of 
programmers, like the phrase 'this sentence will repeat', and it's chopped up to 'this, this, sen, sen, tence, tence, will, will, repeat', and then build up a rhythmic pattern off one chunk of vocabulary. You can compare that idea of working with motivic fragments and developing them to some of the things you hear in contemporary classical music, and definitely in improvisation-the way people develop chunks and fragments and move them around and chop them up.

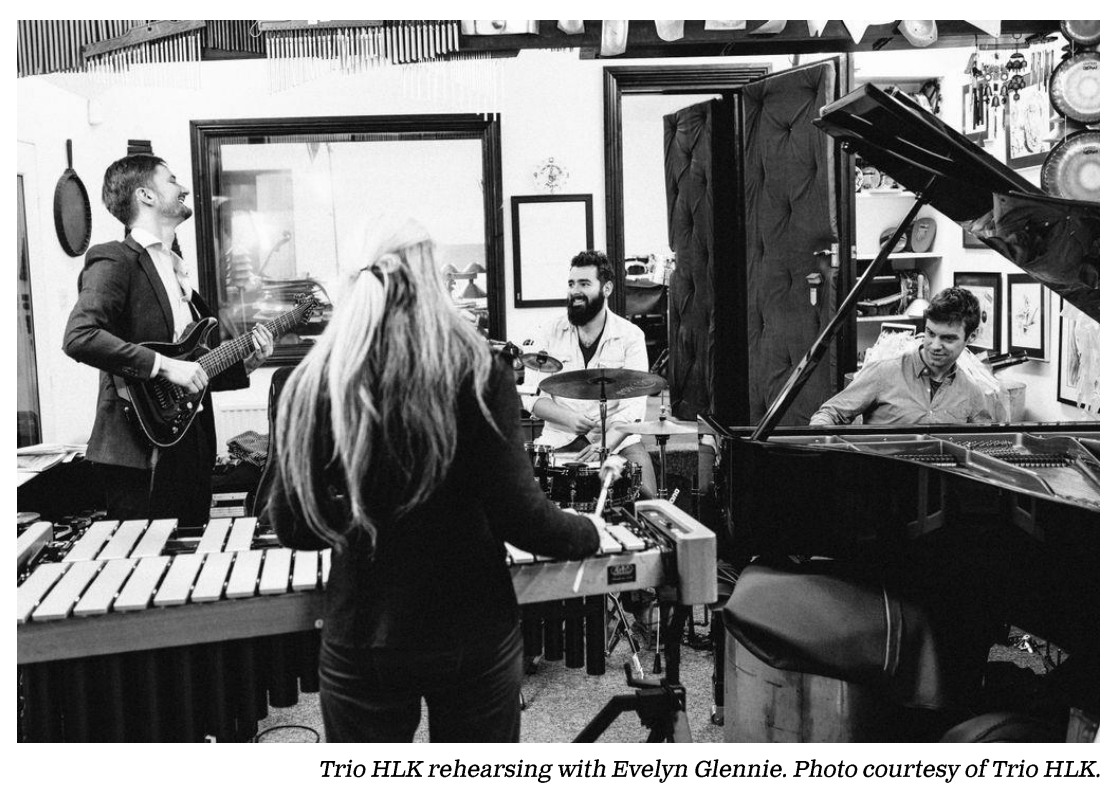

\section{Collaborations and development}

BR: How did your collaborations with Evelyn Glennie and Steve Lehman come about?

RH: We just sent Evelyn some of the music, asked her if she'd be up for it, and she was, and the same with Steve. They were both very, very easy to work with, and incredibly lovely, good-natured, and inspiringly good!

RK: They both commented on how difficult the music wasyou sometimes forget when you inhabit it all the time. Even for those two, who are so incredibly high up musically, some 
of those things might have been unfamiliar, or they might have had to spend some time working on it.

We went to see Steve play at the Bimhuis in Amsterdam, and he did this great microtonal sax intro, and so hearing that vocab led us to ask him to play an intro to one of our pieces. We opened for Chris Potter's trio at Ronnie Scott's back in March for three consecutive nights, and every night we would watch them play, which was so inspiring. The next day we would go and practise and we'd talk about how great their improv was-the different ways they really opened things up-and we'd try to apply some of that to our improv.

We don't just try and make the audience happy, but we do take into account how the audience responds to the music or the flow of the set, and that's had an impact on how we approach the improv sometimes. Thinking back to our first gigs, everything was really full-on all the time, but we've worked on trying to make the set feel balanced in terms of space and intensity. It comes back to having the mental headroom to control what we're doing now that we know the music a lot better than we did at first, when we were probably more concerned with just trying to play the notes correctly. Now, I really make an effort to try and make the music as engaging and as expressively played as possible. That's not saying that if people don't like it we change it-we don't do that at all-but we do try and think about the overall listening experience, even just where we put things in the set, so that people are able to relax and breathe between the more intense passages of music. And again, it comes back to our own experience when we watch music together. We talk about that-how everything flowed and whether we were able to concentrate for the full length of the concert.

RH: It's a funny one that isn't it, having to be aware of the whole gig. Because when I'm working on an individual tune, I'm just thinking about how that tune works in its best 
possible way, but then if you end up with ten very intense tunes, it's not going to work for an audience-well, maybe one or two people. So, it's then a matter of seeing what can be tweaked in order to make the whole thing sit as one performance; it's not easy.

\section{Acknowledgements}

With grateful thanks to Richard Harrold and Richard Kass for generously sharing their time, and for permission to reproduce images and links from the Trio HLK website.

\section{References}

Trio HLK, 2018. [Online]. Available at: 〈http://www.triohlk.com $〉$ [Accessed 16 September 2018].

Ubuntu Music, 2018. [Online]. Available at: 〈http://www.weareubuntumusic.com/trio-hlk-spotify/〉 [Accessed 16 September 2018].

\section{About the author}

BENJAMIN REDMAN is a musician, a teacher, and a $\mathrm{PhD}$ researcher at the Royal Conservatoire of Scotland. His research interests include the use of videoconferencing in instrumental music teaching. He has presented at international conferences, most recently at the Performance Studies Network conference at the Norwegian Academy of Music, Oslo, July 2018. 
Scottish Journal of Performance

Volume 5, Issue 2 


\section{Book review: Reasons to be Graeae: a work in progress, edited by Jenny Sealey}

BEN FLETCHER-WATSON

DOI: $10.14439 /$ sjop.2018.0502.06

Publication date: 30 September 2018

Reasons to be Graeae: a work in progress, edited by Jenny Sealey. London: Oberon Books Ltd, 2018; ISBN: 9781786823946 (£22.50)

Graeae, hailed by playwright Jack Thorne as 'Britain's National Theatre of Disability' (p.283), was founded in 1980. Over the subsequent 38 years, the company has moved from a hardscrabble existence based on project funding to its current position as the UK's leading disabled-led theatre company, touring internationally to great acclaim.

The story of Graeae is not simply one of incremental success leading to longevity. Since the start, the company has fought against patronising ableist attitudes, cynical accusations of positive discrimination, and wild shifts in policy towards people with disabilities. An arts officer for Hampshire County Council, an early funder, claimed in 1982 that 'not to be pro-Graeae is like being in favour of sin' (quoted in Saunders 2015, pp.102-3), but as founder Nabil Shaban notes, today 'the mainstream industry in all honesty does not want [disabled people] on their stages or on their screens' (p.32). Anger and activism drive the narrative throughout Reasons to be Graeae, layering stories of protest with anecdotes of performance. Indeed, the final pages of this book (remarkably, the first text to examine Graeae's history in detail) present the script for a verbatim piece, Sorry, which furiously attacks contemporary social policy 
such as the closure of the Independent Living Fund by the Conservative government in 2015.

Yet it is important to note that this anger has been a powerful force for change. In the words of Colette Conroy:

If we only regret the inflexible structures of theatre, its inaccessibility or its exclusiveness, we position ourselves as helpless functionaries of a pre-existing system. Studying the achievements of disabled cultural activists and artists over the last three decades is important in breaking through this deadlock (p.89).

The book offers readers the chance to do precisely that. Editor Jenny Sealey combines interviews, reviews, images, Top Ten lists, reflections and scripts into a fascinating history of disability-led arts. For example, several pieces note the role of critics, especially Lyn Gardner, as champions of diversity, with statements such as 'There are no limitations here, just glorious liberation' (p.273). Sealey and others go on to skewer certain media figures, including Rhoda Koenig for the Independent and Charles Spencer of the Daily Telegraph, whose attitudes are not as progressive. Adam Hemmings provides a superb brief primer on exclusionary language; he highlights the move from terms like 'handicapped' to the rise of the social model of disability, which begins with the premise that disability is directly caused by the ways in which society is organised, not by any one person's difference or impairment. Without the reclaiming of language by Graeae, it is difficult to imagine the emergence of companies such as Touretteshero, Birds of Paradise and Access All Areas.

Many contributors celebrate the close-knit structures of mutual support that have come to define the company. 
Nickie Miles-Wildin of Manchester's Royal Exchange Theatre declares, 'Graeae is family. It's support. It's people who get it and make work happen' (p.173). 'Family' is a refrain that runs throughout the book, perhaps echoing the original Graeae from Greek myth: three sisters sharing a single tooth and a single eye between them. As evidenced by Sealey's magisterial opening ceremony for the London Paralympic Games in 2012, created in just 14 months of part-time working, the company's training programmes have produced a new generation of $\mathrm{D} /$ deaf, disabled and non-disabled performers. Ex-soldier and amputee Jez Scarratt was taught to use the sway pole for open-air productions, and his chapter serves as a clarion call for their unique model of inclusion: 'I'll never be a big player in the life of cinema, theatre, or performance. But one thing I can assure you, I now love what I do' (p.241).

The book also serves to an extent as a valuable 'how-to' for the industry. For example, Richard Matthews, Head of Marketing and Development, sums up in four pages some basic rules for marketing to D/deaf and disabled audiences that most venues still have not managed to achieve. The company's established blend of British Sign Language, captioning and audio description remains among the greatest contributions to accessibility in the arts of the past 30 years.

There are a few omissions, such as the rise of the neurodiversity movement alongside increased opportunities for training at UK conservatoires and drama schools. Ramps on the Moon, an ongoing movement seeking to revolutionise inclusion of $\mathrm{D} /$ deaf and disabled people within the culture sector, would not have happened without the leadership of Sealey and others from Graeae, but there are only fleeting references to the project here. However, these are minor quibbles. This highly readable and rich text will be of interest to a wide readership, and could as easily 
find its place on theatregoers' bookshelves as on theatre studies reading lists. Contributors from the long history of the company, including actors, administrators, academics and allies, present a tapestry of tales that rightly place Graeae at the very centre of British theatre. I can only echo the words of voice coach Christopher Holt:

...it is for theatre's sake that this company exists. To deliver and provoke art that questions the mainstream, the WASP, the heteronormative, the humdrum. We are the outsiders and the queers and we have power (p.158).

\section{References}

Saunders, G., ed., 2015. British theatre companies: 1980-1994. Joint Stock, Gay Sweatshop, Complicite, Forced Entertainment, Women's Theatre Group, Talawa. London: Bloomsbury Methuen Drama.

\section{About the review author}

DR BEN FLETCHER-WATSON manages the Institute for Advanced Studies in the Humanities at the University of Edinburgh. His research explores performance for non-traditional audiences, including babies, people with dementia and spectators on the autism spectrum. He was a founding editor of the Scottish Journal of Performance. 


\title{
Book review: Gender, subjectivity, and cultural work: the classical music profession, by Christina Scharff
}

\author{
LUCY HOLLINGWORTH
}

DOI: 10.14439/sjop.2018.0502.07

Publication date: 30 September 2018

Gender, subjectivity, and cultural work: the classical music profession, by Christina Scharff. London: Routledge, 2018; ISBN: 9781138942561 (hbk) (£105), ISBN: 9781315673080 (ebk) (£35.99)

This book is an engaging and highly timely analysis of the situation for young women in the classical music profession. I was expecting quite a dry read but I was pleasantly mistaken. Scharff's text is filled with insights both large and small, and she draws on her research to challenge assumptions made by individuals and society more widely.

Through the use of quantitative analysis of datasets and qualitative analysis of interview data, Scharff examines how gender, race and class affect female musicians working in London and Berlin. She critiques inequality, the impact of neoliberal thinking, and the effect of precarious work as they reveal themselves through the interview data. The author also examines solutions and makes proposals for some ways forward in removing obstacles that effectively exclude some members of our society from engaging with cultural work.

The first chapter provides a solid context, based on wider research into cultural work, and explains the Foucauldian approach in which the entrepreneurial individual is understood as entrepreneurial in all aspects of the self, not 
just in an economic sense. Scharff also draws on feminist research which identifies young women as entrepreneurial in the modern world, and therefore concludes that '[a]s cultural workers and young women, my research participants were twice positioned as entrepreneurial' (p.10). She explains how this group of young, female, classical musicians fits into the existing classical hierarchy and how she uses 'critical discursive psychology' (p.26) to find patterns in the interview data of her 64 interviewees.

In Chapter 2, Scharff examines a significant body of quantitative data which reveals the extent of the inequalities in terms of gender and race in members of orchestras and conservatoires in the UK and Germany. She is also interested in what the data does not reveal, such as the socio-economic backgrounds. She presents her analysis of the data in the context of societal obstacles; for example, networking-which disadvantages females, the working class and those from black and minority ethnic backgrounds-and the post-colonial approach to Western classical training in non-Western cultures. Family backgrounds also provide different experiences of consumption of classical music, which also tends to favour the white middle-classes. Mothering is another area of discussion; Scharff argues that this can easily be used as a distraction from the real issue of discrimination against females, and describes the difficulty that women have in presenting themselves as totally committed to a career whether or not they intend to have children.

The next three chapters look in more detail at the interview data, under the sub-headings of class, race and gender, entrepreneurialism, and precarious work. An important theme that emerges from these discussions is the issue of how neoliberal thinking creates a situation where 'gender inequalities were rendered unspeakable' (p.86). The postfeminist woman presents herself as empowered and 
responsible for her own well-being and thus denies that there is any inequality impacting upon her career. Scharff also gives examples of the trivialisation of prejudicial behaviour and stereotyping-one interviewee stated 'you just have to kind of be cool about it' (p.101).

The culture of the entrepreneurial individual can lead to a position such that if the individual is not succeeding, then the reason would seem to lie in personal failure. This attitude conceals a far more complex picture; for example, perceptions of race and class can affect the access an individual has to the resources needed in order to become an entrepreneurial subject, and can reveal the real pattern of dependencies in the society which the entrepreneurial individual disavows.

Scharff describes the idea of the 'the self as business' (p.117) and the impact upon the use of time, physical and mental health (for example the hiding of injuries), the impact of competing with others and with oneself, and the tendency to blame those who are less successful as being responsible for their own failures.

The precarious nature of cultural work and its impact on the ability to plan for the future and to survive financially from month to month is another important theme discussed here. Interviewees manage dire insecurity without feeling able to discuss it with others for fear of admitting difficulty. Some have a financially supportive family to fall back on if necessary, again raising the issue of class as a factor in the accessibility of this type of career. The financial instability and the lack of benefits such as pensions and holidays are balanced against the freedom of being a freelancer and of doing 'the best job in the world' (p.158); the experience of 'being in the zone' (p.161) and the special experience of sharing music with an audience. 
The cultural life and differences between the two cities, London and Berlin, form the final analytical chapter. Of particular interest here is the discussion around how the success of these 'creative cities' (p.172) has led to gentrification and an increase in living costs, which is now threatening the very creative industries that have made the cities centres of culture.

In her concluding chapter, Scharff discusses ways to address some of the issues she has identified; fair pay, insurance schemes for precarious workers, and urban policies protecting creative communities are examples. Maintaining accurate demographic data in order to understand exclusions on racial and gender grounds and a wider debate about exclusion are also suggested. Scharff also recommends 'structural solutions to structural issues' (p.200) and includes here the success of blind auditioning, the use of quotas, and of mentoring and professional development for under-represented groups.

This is a powerful and clearly argued book which touches on issues close to my own experiences as a female classical music composer. It shines a light on unspoken issues and looks at the wider picture of the kind of society we live in and how it affects the female cultural worker. It challenges many contemporary values and suggests that there are political as well as individual issues that need to be addressed. Anyone working in the creative industries, from performers right through to those engaged in forming policy, will find something useful in this book, as will those interested in the social sciences.

\section{About the review author}

LUCY HOLLINGWORTH is a composer, musicologist and writer currently studying for a PhD at the Royal Conservatoire of Scotland. She has a Master's degree in Composition from Edinburgh University. Her research area is autoethnography and women composers and she 
is preparing a creative portfolio and a dissertation. Recent performances include, Out of the Snowstorm, an Owl performed by the Brodick Quartet, What The Living Do performed by Sinae Lee, and a music theatre piece, The Poetess, premiered by students at RCS in 2016 . She previously worked as an IT lecturer and web designer and is the Web Editor of the Scottish Journal of Performance. 
Scottish Journal of Performance

Volume 5, Issue 2 


\title{
Book Review: Musicians in the making: pathways to creative performance, edited by John Rink, Helena Gaunt, Aaron Williamon
}

\author{
BENJAMIN REDMAN
}

DOI: $10.14439 /$ sjop.2018.05.08

Publication date: 30 September 2018

Musicians in the making: pathways to creative performance, edited by John Rink, Helena Gaunt, Aaron Williamon. Oxford: Oxford University Press, 2017; ISBN: 9780199346677 (£47.99)

Musicians in the making: pathways to creative performance is the first in a five-volume series, Studies in musical performance as creative practice, published by Oxford University Press. The other titles in the series are: Distributed creativity, Music and shape, Global perspectives on orchestras, and Music as creative practice. The series has its origins in a large research project which ran from 2011 to 2014 at the Arts and Humanities Research Council (AHRC) Research Centre for Musical Performance as Creative Practice (CMPCP). The project's main aim was 'to investigate how the "creative voice" of individual musicians develops over time' (p.xxi). The series is a definitive outcome of the project, and is a major achievement for British music education publishing.

The project's research questions included:

- How can the knowledge and skill acquired in the teaching studio, practice room and classroom be used to maximum benefit in performance? 
- What learning and teaching techniques are most conducive to transmitting the musical skills and knowledge required to surpass the routine and predictable in musical performance?

- Should 'creative performance' necessarily be considered the main artistic goal for each and every performer? (p.xxi).

In the preface to Musicians in the making, the editors acknowledge the difficulty and complexity of these questions; in attempting to answer them they engaged with a wide range of authors, including many internationally renowned researchers, performers, and academics. Of particular note are the ten 'insights' that individual performers and performance teachers share from their own personal lived experiences. They come from a diverse mix of musicians, including former Principal of the Royal Conservatoire of Scotland (RCS), John Wallace, and international concert pianist, Melvyn Tan. Pianist and conductor Ricardo Castro provides a quote which, as a teacher, particularly resonates with me:

It is essential to give children and young musicians the feeling that they have the right to be creative. Otherwise they become robots, repeating other people's work. And if they are only copying others, it becomes almost impossible for them to feel necessary or relevant to the community (p.136).

These personal testimonies are welcome in an academic text; their inclusion gives life and vitality to this volume, and perhaps make it more appealing to a broader audience than some of the other, more academic, volumes in the series. 
Musicians in the making consists of 16 chapters, organised into three parts:

1. Creative learning in context.

2. Creative processes.

3. Creative dialogue and reflection.

There is no shortage of fascinating material to discuss, including: creative spontaneity, interpreting a composer's intentions, and developing a greater awareness of audience responses. I have chosen three chapters by authors who will be familiar to readers in Scotland. Firstly, in 'A musician's journey', John Wallace traces his own path as a musician, from being given his first cornet aged seven and joining the local Tullis Russell Mills Junior Band, through his formative years at Buckhaven High School in Fife, which he describes as being 'an underground arts factory filled with a powerhouse of inspired individuals' (p.1). Of his cultural background, he writes: 'Music suffused everything: it was part of our family, it pulsated through the veins of our community. It wasn't a polite, civilising add-on: it was the glue of society. It held us together' (p.2). He describes his tenure as the Principal of the RCS (from 2002-2014) thus:

Making work and play-making in a conservatoire like Scotland's means being surrounded by musicians, actors, dancers, technical designers, scenic artists and film makers every day, at every age and stage. Immersion in a conservatoire reminds me of the society I grew up in (ibid.).

Whilst being inspired by Wallace's testimony, I find myself in despair about the current austerity measures in the UK, and what the cutbacks to schools and music services across Scotland mean for the next generation of musicians who are 
sadly missing out on the breadth and depth of experiences he describes.

In 'Reflection and the classical musician', Mary Hunter and Stephen Broad examine 'the notion of reflective practice' (p.253), and how this can assist the classical musician in reconciling the competing demands of making interpretative choices, whilst also remaining true to a composer's intentions on the written score. The chapter is based on self-reflections from a sample of students at the RCS and interviews with professional musicians. The authors discuss the distinction between 'reproduction' and 'realisation' of a classical score: 'Too much invention and you're out of bounds, but too literal an understanding of historical obligation and you're equally wrong' (p.268). They note a possible generational shift towards younger performers taking more responsibility for, and being more confident in, making interpretative decisions 'as a more explicitly discursive process, a dialogue with the material and the content' (p.267).

In 'Towards convergence', Celia Duffy and Joe Harrop discuss the increasing convergence between musicianship studies and academic studies in higher education learning environments. They asked a range of early career professionals, as well as professors of academic and performances studies across institutions from the UK, USA and New Zealand, 'whether and how academic studies might influence performance, inform performers' choices or even lead to more creative performances' (p. 272). They choose a working definition of a creative performance as one that is 'independent, individual, challenging, thoughtful, risky, enlightening and disturbing, offering new light on the music' (p.272), and describe the 'Style in performance' module delivered at RCS as 'an environment in which critical, informed experimentation (rather than "getting it right”) was encouraged' (p.278). The authors acknowledge 
the difficulty of bringing about a more unified approach to these previously compartmentalised disciplines, but suggest:

\begin{abstract}
Integrated teaching strategies may at least nudge some student performers into thinking twice when confronted with academic studies or an academically informed viewpoint, before protesting 'but I need to practise!' or 'I just feel it this way'. Others will relish the integrative intellectual and creative challenge of musical praxis (p.286).
\end{abstract}

These two chapters demonstrate some of the ways in which reflective and informed thinking, and the convergence of academic studies with performance studies, can indeed lead to 'pathways to creative performance'.

As in the above examples, there are (perhaps inevitably) some areas of overlap between the chapters; whilst this adds to the richness of the topics discussed, other equally valid topics such as jazz improvisation are perhaps less well represented in this volume. However, Musicians in the making is an invaluable repository of fresh, imaginative, deep, and critical thinking about the training and professional lives of music performers and teachers. In addition to its value to scholars and researchers, it will appeal to anyone concerned with the creation and performance of music, the training of musicians, and an interest in creativity and the creative process.

\title{
About the review author
}

BENJAMIN REDMAN is a musician, a teacher, and a $\mathrm{PhD}$ researcher at the Royal Conservatoire of Scotland. His research interests include the use of videoconferencing in instrumental music teaching. He has presented at international conferences, including the Performance 
Scottish Journal of Performance

Volume 5, Issue 2

Studies Network conference at the Norwegian Academy of Music, Oslo, July 2018. 